\title{
LOS RELIEVES DE ARMAS DEL TEATRO DE MERIDA*
}

\author{
FABIOLA SALCEDO GARCES \\ Instituto de Arqueología «Rodrigo Caro» \\ del C. S. I. C. (Madrid)
}

\begin{abstract}
El objeto de este trabajo es el estudio de dieciséis fragmentos de mármol blanco tallados en relieve y representando el tema de las «armas amontonadas» o congeries armorum. El valor cultural que las armas pueden llegar a adquirir, justifica que el propósito fundamental aquí marcado haya sido el estudio iconográfico e iconológico de las piezas.

Como parte de este estudio y como objetivo secundario en sí mismo es el análisis estilítico de los relieves para mostrar una vez más que el estudio del lenguaje de las formas artísticas en el mundo antiguo es susceptible de aportar una sistematización cronológica. Se analiza también uno de los apoyos fundamentales ampliamente utilizados por algunos autores para fechar tanto estas piezas como otras: el contario "canónico».

The object of this work is the study of sixteen white marble pieces in relief and representing the theme «surmounted weapons» or congeries armorum.

The relation with worship that weapons can become getting, justifies that the main purpose here has been the iconographical and iconologycal study of the pieces.

As part of this objective and as one secondary in itself is the stilistic analysis of the reliefs in order to show once again that the study of artistic forms language in ancient world is susceptible of offering chronological systematization. It's been here analysed too, one of the most important supports used by some authors to date not only these pieces but others as well: the «canonical contario» or perlstab.
\end{abstract}

La colonia Iulia Augusta Emerita (LE ROUX, 1982, 69-72), fundada por Augusto y destinada a ser capital de la Lusitania, se convirtió además en uno de los centros culturales más importantes de la Hispania Romana (1).

Entre el abundante material arqueológico que ha ofrecido y sigue ofreciendo, un capítulo relevante lo constituyen las numerosas piezas artísticas entre las que hay que incluir el conjunto de relieves que aquí se va a estudiar.

Quiero destacar de manera especial mi agradecimiento al doctor Arce por su constante interés y eficaz orientación en la realización de este estudio. Igualmente agradezco al profesor M. Bendala sus muy valiosas indicaciones sobre la configuracion del trabajo; al señor Sáenz de Buruaga, su amabilidad por facilitarme el estudio de los materiales en el Museo de Mérida; a los doctores W. Trillmich y D. Hertel, sus diversas atenciones, en especial la de haberme proporcionado la documentación fotográfica; a Nivio López Vigil agradezco la realización de los dibujos. Finalmente a Miguel Angel Elvira, Filippo Coarelli, Marta Hernández y Marga González, sus apreciables sugerencias.

(1) Tradicionalmente se ha considerado el año $25 \mathrm{AC}$ como fecha de fundación de la colonia, pero una revisión llevada a cabo por J. Arce la sitúa entre el fin de las guerras cántabras - 19 AC y el año 16 AC- - fecha de la inscripción del teatro. Véase (ARCE, 1984). 
Este conjunto, integrado por dieciséis fragmentos de mármol blanco, muestra un tema decorativo consistente en la representación de armas de distinto tipo: corazas, escudos, cascos, espadas...

Aunque es imposible el ensamblaje de unas piezas con otras, no cabe duda de que pertenecen a una misma unidad. No sólo el material y el tema son los mismos en todas ellas, sino que también los criterios de ejecución estilística se mueven en una única dirección. Finalmente, todo el conjunto -aunque desconocemos el número exacto de piezas - fue encontrado en la zona del peristilo del teatro y en las proximidades de una estancia - si no en ella misma- que Antonio Floriano, excavándola más tarde, en 1936, definió como una biblioteca (FLORIANO, 1944, 160).

Las referencias - anteriores al presente estudio- que tenemos de estos relieves son diversas. La primera de ellas se debe al informe de las excavaciones que, entre 1929 y 1931, Mélida y Macías llevaron a cabo en la zona del peristilo. De esta breve noticia se desprende, no obstante, que los relieves debieron salir a la luz con anterioridad a aquella fecha, quizá durante las labores de prospección y sondeo que empezaron a realizarse en esta zona simultáneamente a la excavación del teatro (MELIDA y MACIAS, 1932, 13).

Sabemos también por estos dos investigadores y por Lantier (LANTIER, 1918, 25; MACIAS, 1929, 99, f. 34) que, después del descubrimiento, el conjunto pasó a formar parte del «Museo del Teatro», aunque ignoramos cuántos de los dieciséis fragmentos que aquí se estudian fueron allí depositados; la noticia más completa desde este punto de vista cuantitativo - la de Lantier - sólo se refiere a seis de ellos. La mayoría de los comentarios, además, se han centrado fundamentalmente en el fragmento núm. I, y fue éste precisamente el único que pasó a exponerse al público cuando se trasladaron los relieves a uno de los almacenes del Museo de Arte Romano.

Además de Mélida, Macías y Lantier, otros investigadores, como P. León (LEON, 1970, 181), A. Blanco (BLANCO, 1982, 610, f. 309), M. Wegner (WEGNER, 1961, 271, f. 54, 3) y G. Traversari (TRAVERSARI, 1971, 76, nota 175), han tratado sobre parte de este conjunto en alguna ocasión. Aunque sus noticias han sido muy breves, es de subrayar que todos ellos han coincidido unánimemente en resaltar una característica de enorme importancia: la excelente ejecución y delicadeza de la talla.

El objetivo que nos hemos marcado en este trabajo ha sido el de estudiar estas piezas de una manera lo suficientemente exhaustiva como para posibilitar, por una parte, la extracción de una serie de datos de tipo político y social y, por otra, resolver el problema planteado en relación con la cronología de estos relieves.

Para alcanzar esta doble meta, hemos comenzado por el estudio anticuarístico de la morfología de las armas, analizando después sus diferentes temas decorativos. La información de carácter político, social y simbólico que de aquí se extrae se complementa, en este mismo sentido, con los datos relativos al lugar donde las piezas aparecieron.

En cuanto a la datación de los relieves, hemos tomado como punto de partida la asignación que algunos de los especialistas propusieron - la época flavia- y hemos tratado de analizar los argumentos utilizados para asentar tal afirmación. Uno de ellos es la hipotética cronología que el contario «canónico» puede ofrecer; los otros, son los referentes al amplio ámbito del análisis estilístico, en cuya problemática hemos intentado entrar.

\section{MORFOLOGIA Y DECORACION DE LAS ARMAS}

La identificación de los diferentes objetos que se representan en los relieves se ha apoyado, en gran parte, en la sistematización tipológica que Willen Crous ha establecido en su estudio sobre las pilastras del Armilustrum del Aventino (WILLEN, 1933, 
1-119). No voy a entrar en la descripción de todos estos objetos ya que para ello pueden consultarse las ilustraciones, en las que se ha intentado además una reconstrucción hipotética del armamento. Tan sólo van a ser objeto de comentario aquellos elementos que por su particularidad o significado ofrezcan un cierto interés.

\section{Fragmento núm. I}

La base de este fragmento está constituida por un marco de ovas y carretes o «sombrerillos» de forma piramidal. Este contario, denominado "canónico» por Wegner (WEGNER, 1957, 47), lo veremos delimitando gran parte de los fragmentos de este conjunto.
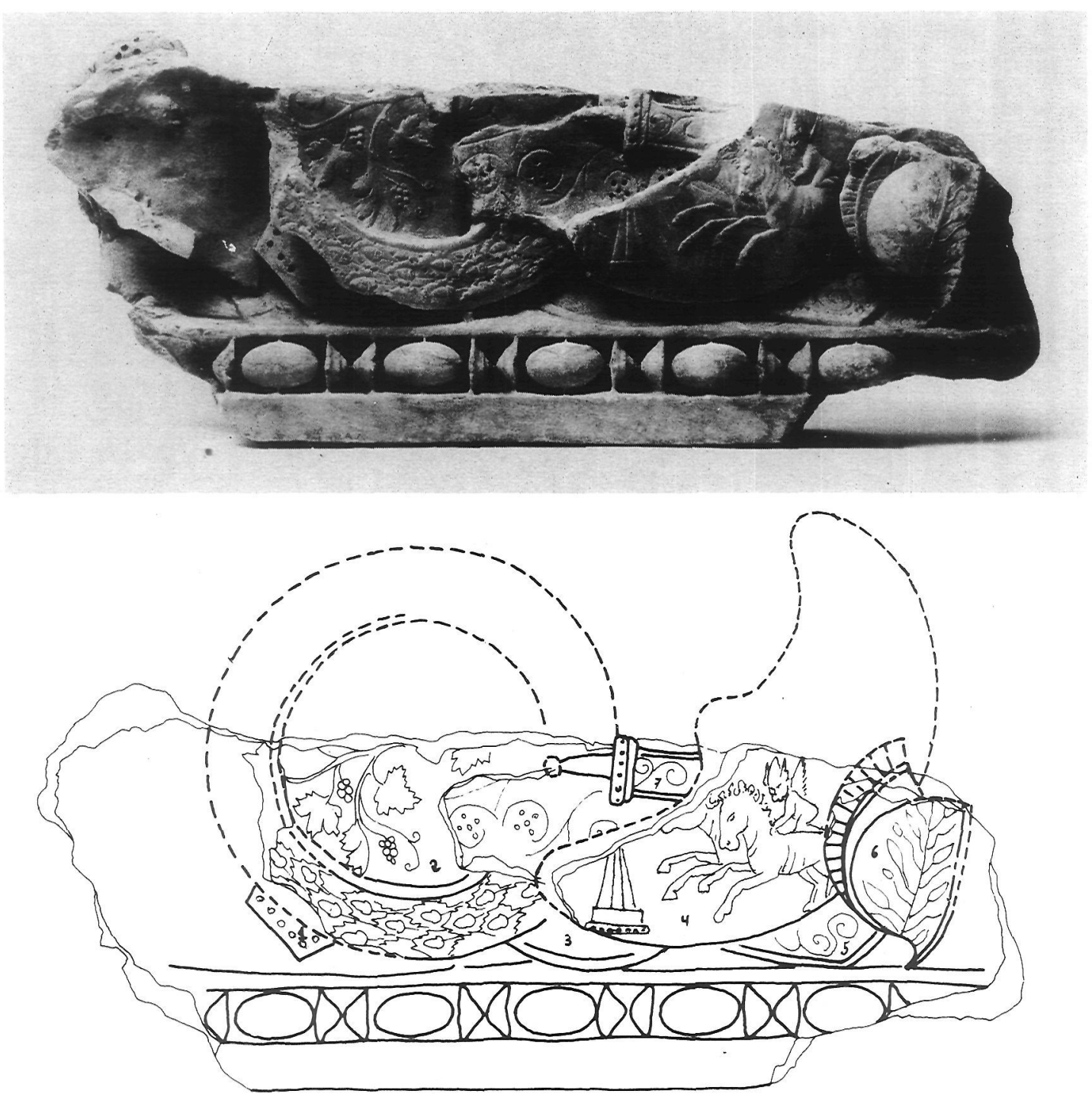

Fragmento núm. I. Dimensiones: long., $44 \mathrm{cms}$; ancho, $9 \mathrm{cms}$; alto, $17 \mathrm{cms}$. Número 1 , base de escudo exagonal u ovalado de extremos planos; 2 , pátera ritual; 3 , base de escudo ovalado; 4 , pelta; 5 , ángulo de la base de un escudo ovalado de extremos planos; 6 , casco con penacho; 7 , espada enfundada. 
Por encima de esta línea de base, los elementos morfológicos más interesantes son: Núm. 2.-Objeto de tendencia curvilínea decorado con racimos de uvas, pámpanos y zarzillos. El borde, constituido por una franja sobresaliente, está decorado con la «corona cívica» - hojas de encina y bellotas.

Casi con toda seguridad, se trata de una pátera ritual como el disco de plata de Kerch (STRONG, 1966, pl. 63 A) o el disco de Cesena (STRONG, 1966, pl. 58 A).

Núm. 4.-Pelta de contornos simples decorada con una escena circense en la que un putto ornado con el pileus, brida dos caballos al galope, y otro le espera al lado de la meta. El borde de esta pelta - que es también el de otros muchos escudos- es el que hemos denominado «de cordón fragmentado».

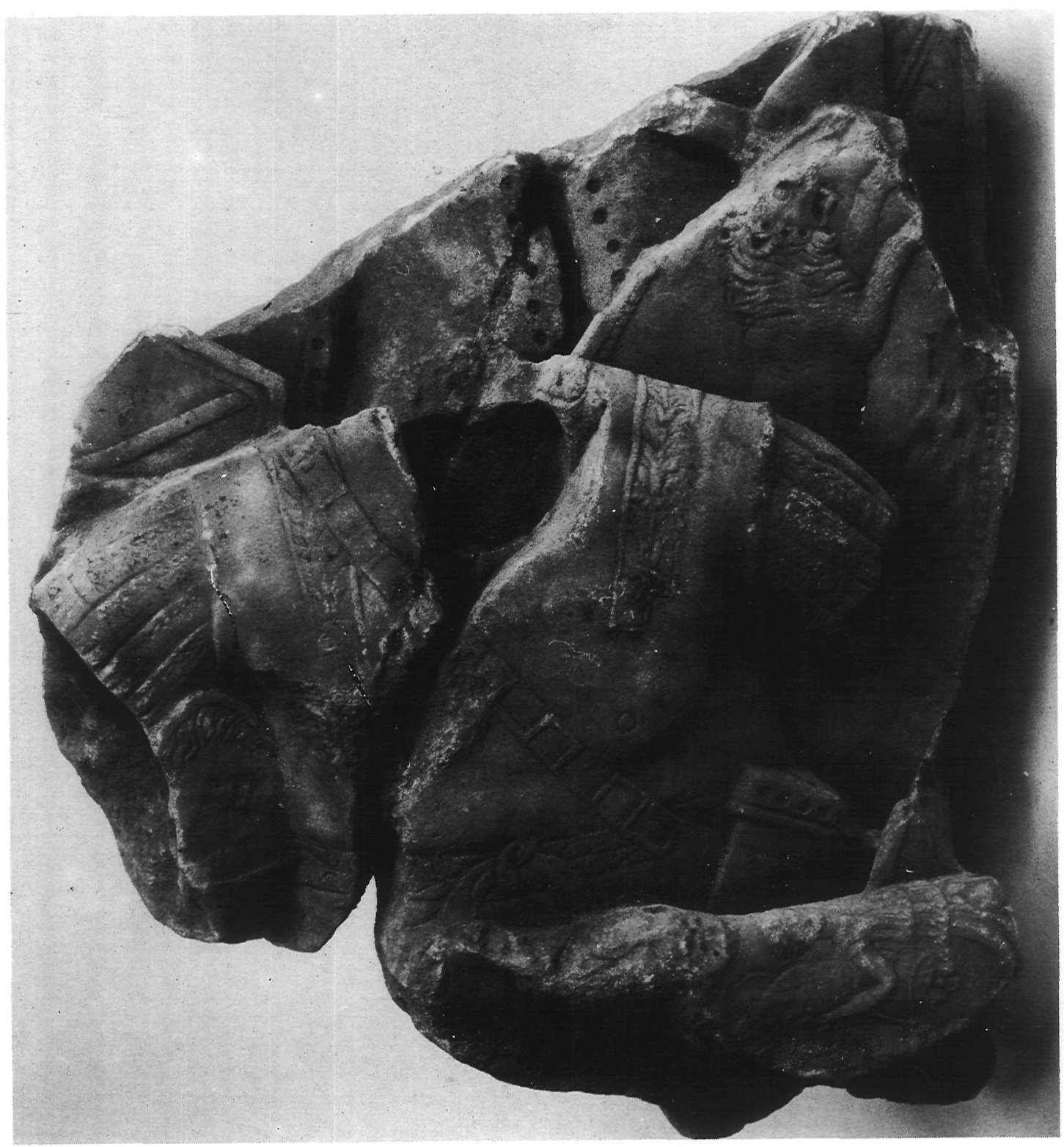


Fragmento núm. II

Núm. 8.-Objeto trianguliforme de ángulos redondeados en el que se representa la cara de la Medusa Gorgona. Constituiría la carrillera derecha de un casco. Un ejemplo ilustrativo lo tendríamos en el tipo 16 y 17 de los cascos de las pilastras del Aventino de la galería de los Uffizi (WILLEN, 1933, 78 y 79).

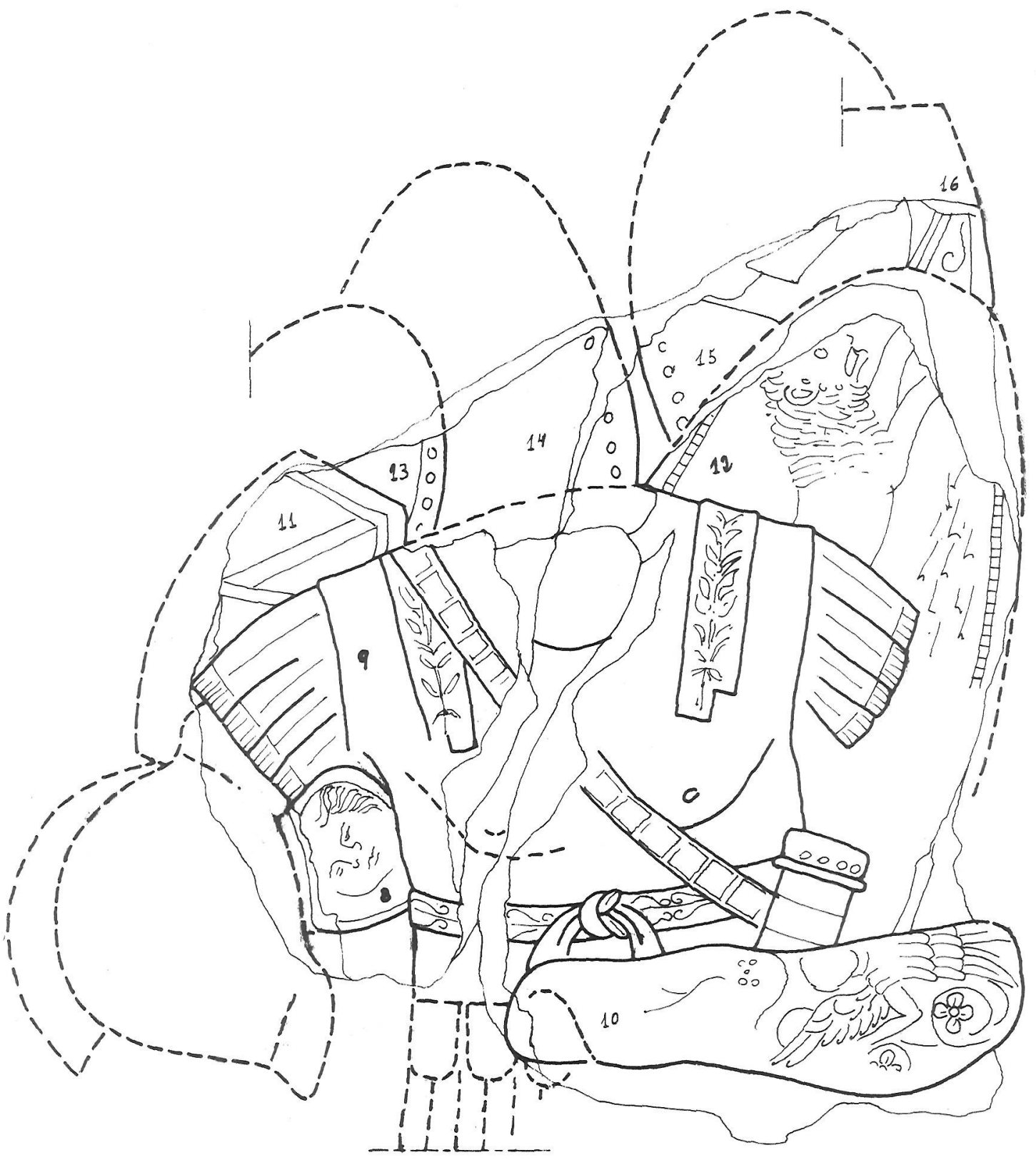

Fragmento núm. II. Dimensiones: long., $21 \mathrm{cms}$; ancho, $7 \mathrm{cms}$; alto, $23 \mathrm{cms}$. Número 8 , carrillera de casco; 9 , coraza musculada; 10 , ocrea; 11 , escudo ovalado de extremos planos; 12 , escudo plano ovalado bordeado con el diseño de «cordón fragmentado»; 13, 14 y 15 , escudos ovalados; 16 , escudo ovalado de extremos planos. 
Núm. 11.-Angulo superior derecho de un escudo ovalado de extremos planos. El doble reborde escalonado descendente hacia la zona central y la presencia de una franja rectilínea que atraviesa dicha superficie central en sentido diagonal sugiere que se trata de un escudo representado desde el interior, en que la correa de sujeción sea la franja rectilínea.

Núm. 9. - Coraza musculada de tipo helenístico exenta de decoración en el torso y a la que se suman los siguientes elementos formales:

- Balteus decorado con un diseño de meandro continuo. De él pende, por el costado izquierdo de la coraza, un puñal o espada envainada a la que le falta la empuñadura.

- Cingulum decorado con volutas enlazadas y anudado en su zona central.

- Humerales o correas que unen la coraza por su parte superior. Están decorados con una sucesión de lotos enlazados en sentido vertical. - Launas o correas de cuero que terminan en flecos e irían unidas a la coraza por pequeños remaches.

Por estos elementos formales, podríamos paralelizar este tipo de coraza con el tipo 40 de las pilastras de los Uffizi (WILLEN, 1933, taf. 12-519).

El estudio de los torsos thoracatos de tipo helenístico presenta una problemática especial que merece ser tratada con cierto detenimiento. Abordaremos, por tanto, este punto más adelante.

Núm. 10.-Ocrea o greba - similar a la del tipo V de las pilastras de los Uffizi (WILLEN, 1933, 74) - y cuya característica es la adaptación anatómica. En la zona de la rodilla se encuentra tallada una cara imberbe -quizá la de la Medusa Gorgona, como es frecuente en las ocreas de este tipo-. En el área de la pantorrilla una Victoria alada vistiendo el peplo y portando una corona en su mano derecha.

\section{Fragmento núm. III}

Núm. 17.- Mitad derecha de una pelta en la que se ha representado una guirnalda profundamente trepanada y enganchada al cuerno derecho de un carnero. Un águila con las alas plegadas yergue su cuello en sentido perpendicular a su cuerpo para mirar la guirnalda. El extremo visible de la pelta está decorado con una palmeta estilizada. Otros elementos como roleos y objetos filamentosos ornamentan el fondo neutro de la pelta.

Núm. 22. - Cabeza de ave que constituiría la empuñadura de una espada o quizá parte de un instrumento musical.

Como parte de la decoración del núm. 23. - Punta de lanza muy parecida al tipo de Sigmaringen (COUSSIN, 1926, 361, f. 108) y al tipo 31 de las pilastras Uffizi (WILLEN, 1933, 83). Algunas de estas lanzas pueden aparecer como decoración en relieve de escudos (WILLEN, 1933, taf. 12-489).

Núm. 19.-Mitad superior de un panel cuadrangular cuyo centro está perforado en forma de círculo. Bordea este círculo central una franja decorada con la «corona cívica». Igualmente, el borde del panel consiste en una franja decorada con una sucesión de espirales o eses afrontadas. Un diseño muy similar lo encontramos en algunos vasos ibéricos posteriores al siglo III AC y de influencia helénica (JORGE ARAGONESES, 1968-69, 200). El ángulo visible de la franja presenta una protuberancia cuya zona inferior se halla enormemente trepanada y la superior muestra dos cuerpos de forma casi anular que se enlazan.

Este objeto, cuyo único paralelo lo hemos encontrado en las pilastras de los Uffizi, serviría probablemente como escudo protector a través de cuyo orificio se accionaría la lanza (WILLEN, 1933, taf. 10-415). Algunos de estos paneles podían tener como decoración de sus ángulos, grifos o anillos - como parece es este caso (WILLEN, 1933, taf. 2-85). 

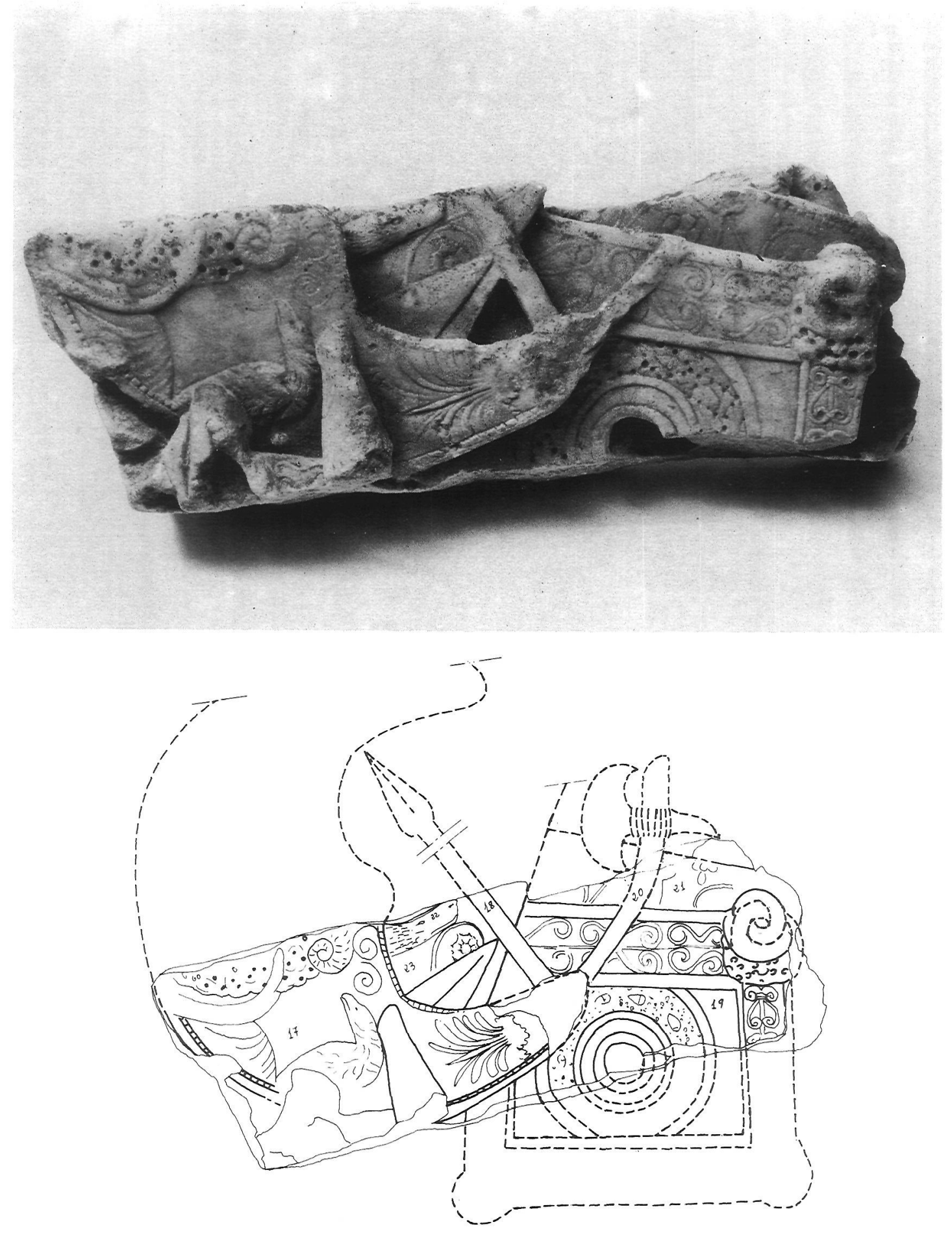

Fragmento núm. III. Dimensiones: long., $28 \mathrm{cms}$; ancho, 9,5 cms; alto, 7,5 cms. Número 17, pelta; 18, mástil de lanza o pilum; 19, panel de artillería; 20, hacha; 21 , superficie de escudo plano; 22, cabeza de ave (instrumento musical o empuñadura de espada); 23, superficie plana decorada de un escudo. 

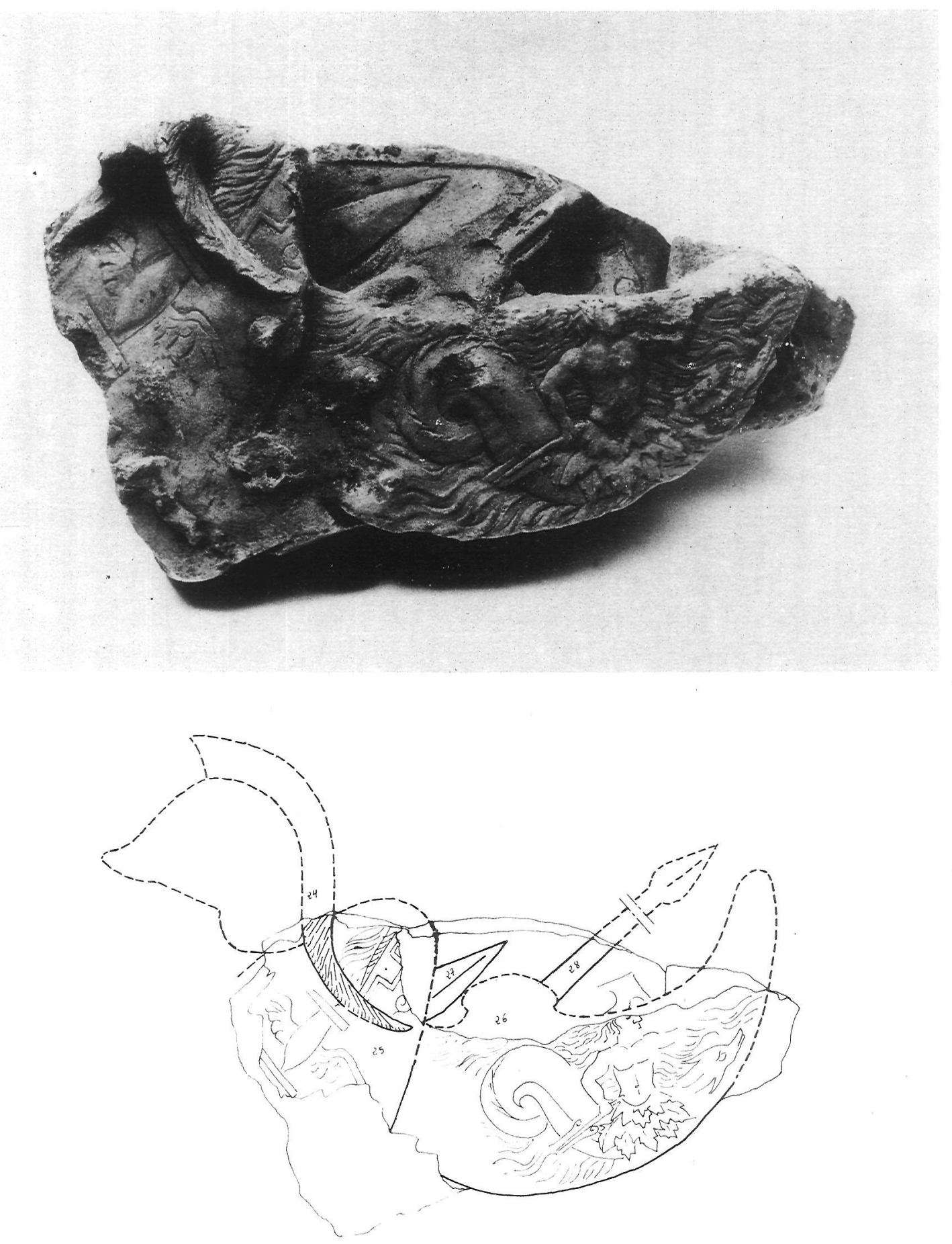

Fragmento núm. IV. Dimensiones: long., $28,5 \mathrm{cms}$; ancho, $7 \mathrm{cms}$; alto, $15 \mathrm{cms}$. Número 24, penacho de casco; 25 , escudo ovalado decorado con el rayo y el águila de Júpiter; 26 , pelta; 28 , mástil de lanza o pilum. 


\section{Fragmento núm. IV}

Núm 26.-Pelta cuyo borde ha desaparecido por completo. Se representa en ella una escena marina en la que el protagonista es un tritón acompañado de un delfín.

\section{Fragmento núm. V}

Núm. 29.-Objeto hemisférico representado en planta. El cincel, en este caso, ha descrito una serie de franjas concéntricas de mayor o menor anchura en las que se ha realizado una labor de incisión en sentido radial y que da a la pieza un aspecto de cabellera. Cortando el objeto en forma tangencial aparece una especie de lengüeta de aspecto lanceolado que descansa sobre el objeto hemisférico.

Este objeto de difícil identificación se ha podido definir como un casco de caballería auxiliar. Los ejemplos en los que nos hemos apoyado han sido los siguientes:

- Casco del Museo del Mittelrhein, Koblenz (2).

- Estelas de caballería auxiliar: C. Romanius, Mittelrheinisches Landesmuseum, Mainz (RUSSEL, 1975, pl. 302); T. Flavius Bassus, Colonia (ROBINSON, 1975, pl. 301); estelas de Worms (ROBINSON, 1975, pl. 297 y 299); estela del Römisches-Germanisches Museum, Colonia (ROBINSON, 1975, pl. 301).

- Cascos en los trofeos de Pompeya (PICARD, 1957, pl. XIII).

- Arco de Orange. En los paneles de armas de las fachadas noroeste, nordeste y sudeste, aparece también este tipo de casco, ilustrándonos
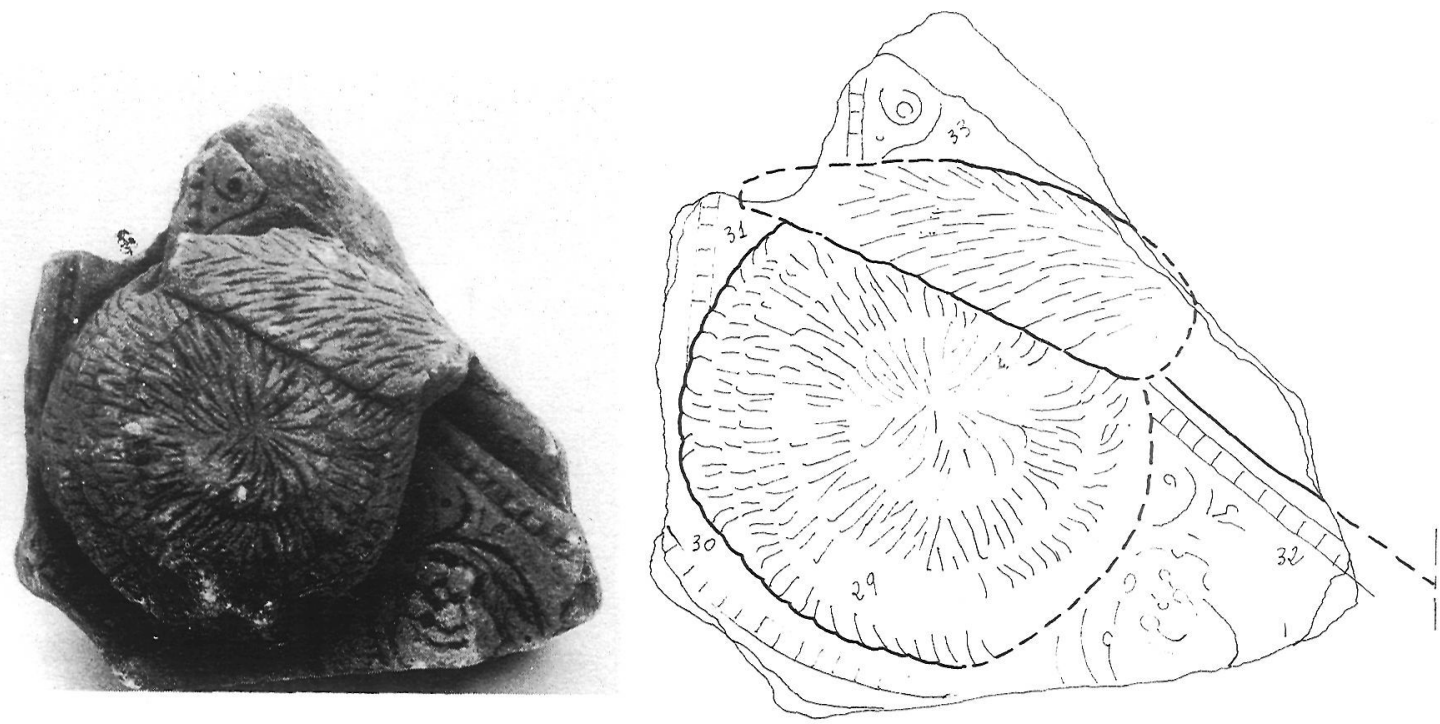

Fragmento núm. V. Dimensiones: long., 13,4 cms; ancho, 8,8 cms; alto, 10,8 cms. Número 29, casco de piel usado por la caballería auxiliar; 30 , escudo convexo representado desde el interior; 31 , fragmento de escudo; 32 y 33 , fragmentos de escudos.

(2) La cubierta de este casco es de bronce; h.: $11,8 \mathrm{~cm}$.; $1 .: 23,3 \mathrm{~cm}$. Invent. núm. 5.875 . (KLUMBACH, 1974, taf. 32). 
además sobre la función de esa lengüeta que aparece aquí superpuesta y que no es otra cosa que una carrillera de gran flexibilidad (AMY, DUVAL, ..., 1962, pl. 43: 1c, IIf, IIg, IIh, IVf, IVg; pl. 16, 17 y 18).

Este tipo de casco podía ser tanto de metal como de piel real.
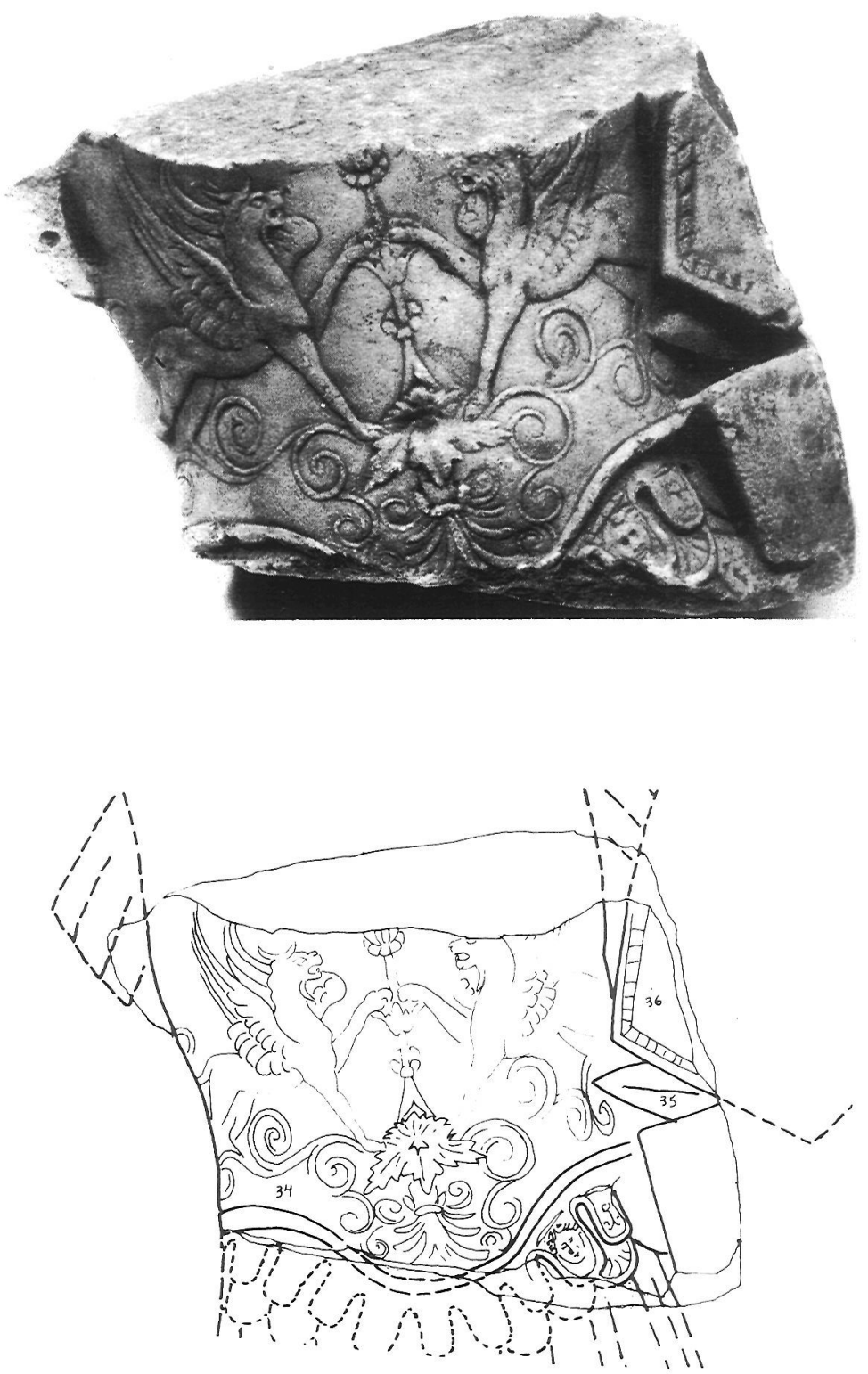

Fragmento núm. VI. Dimensiones: long., $14 \mathrm{cms}$; ancho, $8 \mathrm{cms}$; alto, $12 \mathrm{cms}$. Número 34 , coraza musculada imperial; 35 , punta de lanza; 36 , ángulo izquierdo de un escudo ovalado de extremos planos. 


\section{Fragmento núm. VI}

Núm. 34. - Parte inferior de una coraza musculada de tipo helenístico. Se conservan restos de dos filas de lambrequines o pteryges superpuestos. Los de la fila superior tienen forma de lengüeta de extremo cuadrangular; los de la hilera inferior muestran un perímetro semicircular. Se decoran con cabezas de Medusa y con palmetas estilizadas.

El motivo iconográfico central de este torso lo constituye un esquema heráldico de dos grifos que levantan una de sus patas delanteras (la derecha y la izquierda respectivamente), apoyándolas sobre un tallo de flores que hace las veces de eje de simetría. El extremo inferior del tallo descansa sobre una hoja de acanto de la que parten hacia ambos lados ramificaciones de roleos enlazados, y por su parte inferior una palmeta, también con roleos.

Los detalles de esta coraza se tratarán más tarde.

\section{Fragmento núm. VII}

Núm. 37.-Parte superior de una coraza musculada de tipo helenístico. Sobre ella aparecen las correas o humerales decorados con un diseño de lotos enlazados. El torso deja traslucir por su hombro derecho el colobium. Además de decorada con roleos, el tema principal lo constituye la cabeza de la Medusa Gorgona.
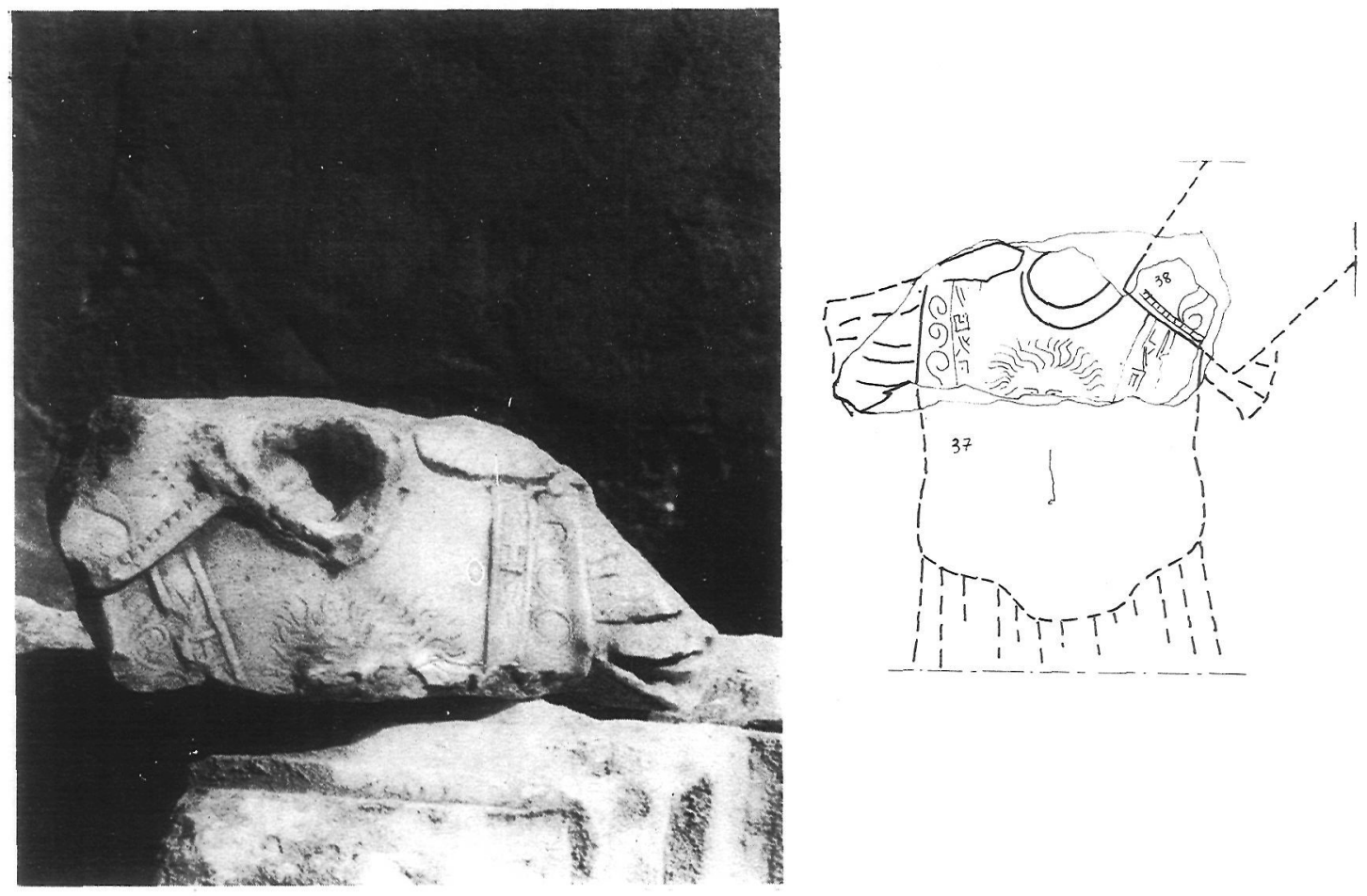

Fragmento núm. VII. Dimensiones: long., 17,2 cms; ancho, $7 \mathrm{cms}$; alto, 7,5 cms. Número 37, parte superior de una coraza musculada imperial; 38 , base de un escudo. 


\section{Fragmento núm. VIII}

Núm. 39.-Objeto trianguliforme de volumen ligeramente curvo. En el lado de la supuesta base aparece una franja de anchura decreciente en la que se representa un banco de delfines nadando en medio de las aguas, sugeridas con leves sinuosidades, como en el fragmento $n .^{\circ}$ IV.

No hemos podido identificar este objeto de manera clara aunque es posible que se trate de una proa (WILLEN, 1933, 104).

Este fragmento presenta la particularidad de constituir una de las esquinas o ángulos del panel. El marco es, por tanto, el contario «canónico» mostrando la peculiaridad de la composición del ángulo mediante la unificación de dos ovas en una, resultando así un cuerpo angular decorado por una hoja de acanto.
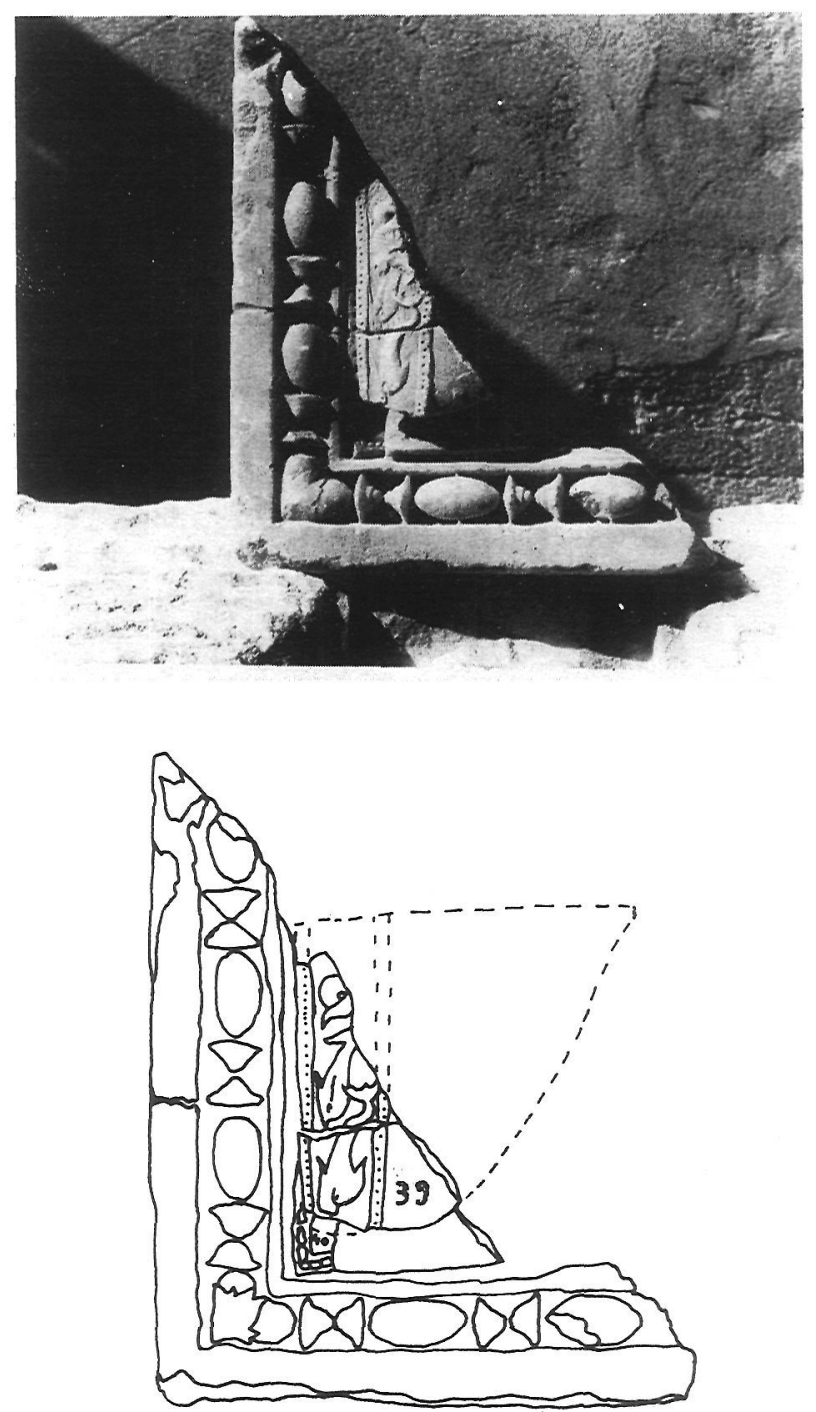

Fragmento núm. VIII. Dimensiones: long., 20,5 cms; ancho, $7 \mathrm{cms}$; alto, $25,3 \mathrm{cms}$. Números 39 y 40 , bases de escudos. 


\section{Fragmento núm. IX}

Núm. 41. - Cuerno acústico decorado en su parte más ancha con un perro a la carrera, roleos y hojas; en su zona más estrecha aparecen las estribaciones de una cabellera. Se puede comparar con el tipo 105 de las' pilastras Uffizi (WILLEN, 1933, 104).
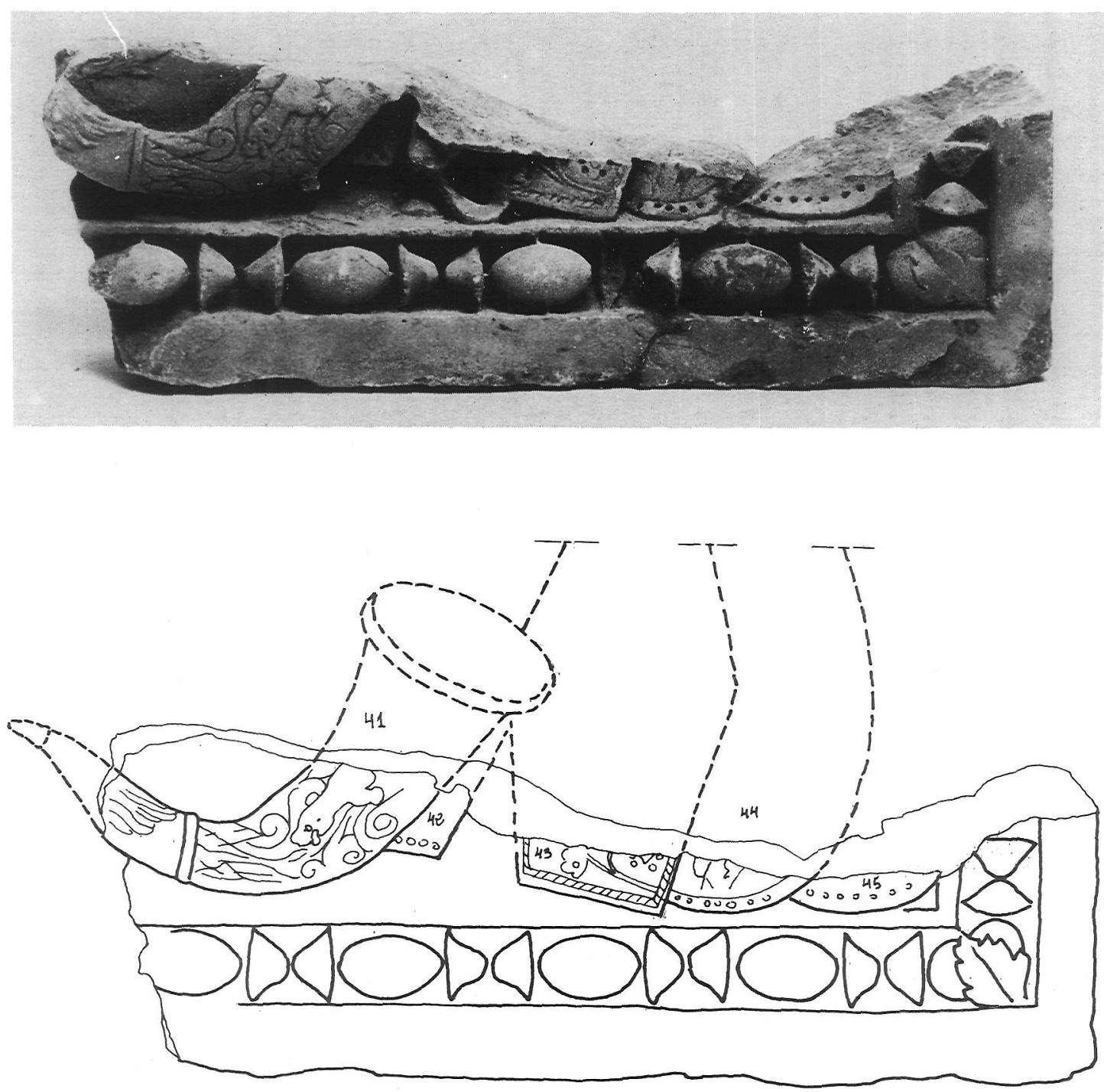

Fragmento núm. IX. Dimensiones: long., $32 \mathrm{cms}$; ancho, $7 \mathrm{cms}$; alto, $11 \mathrm{cms}$. Número 41 , cuerno acústico; 42, ángulo derecho de un escudo exagonal u ovalado de extremos planos; 43 , base de escudo exagonal; 44 , base de escudo ovalado; 45 , base de escudo ovalado. 


\section{Fragmento núm. X}

Núm. 49.-Trompeta de guerra en forma de cabeza de dragón, de origen gálico, denominada carnyx.

La encontramos en el panel del trofeo lateral este del arco de Orange (AMY, DUVAL, ..., 1962, pl. 44) y en las pilastras Uffizi (WILLEN, 1933, taf. 9-338).
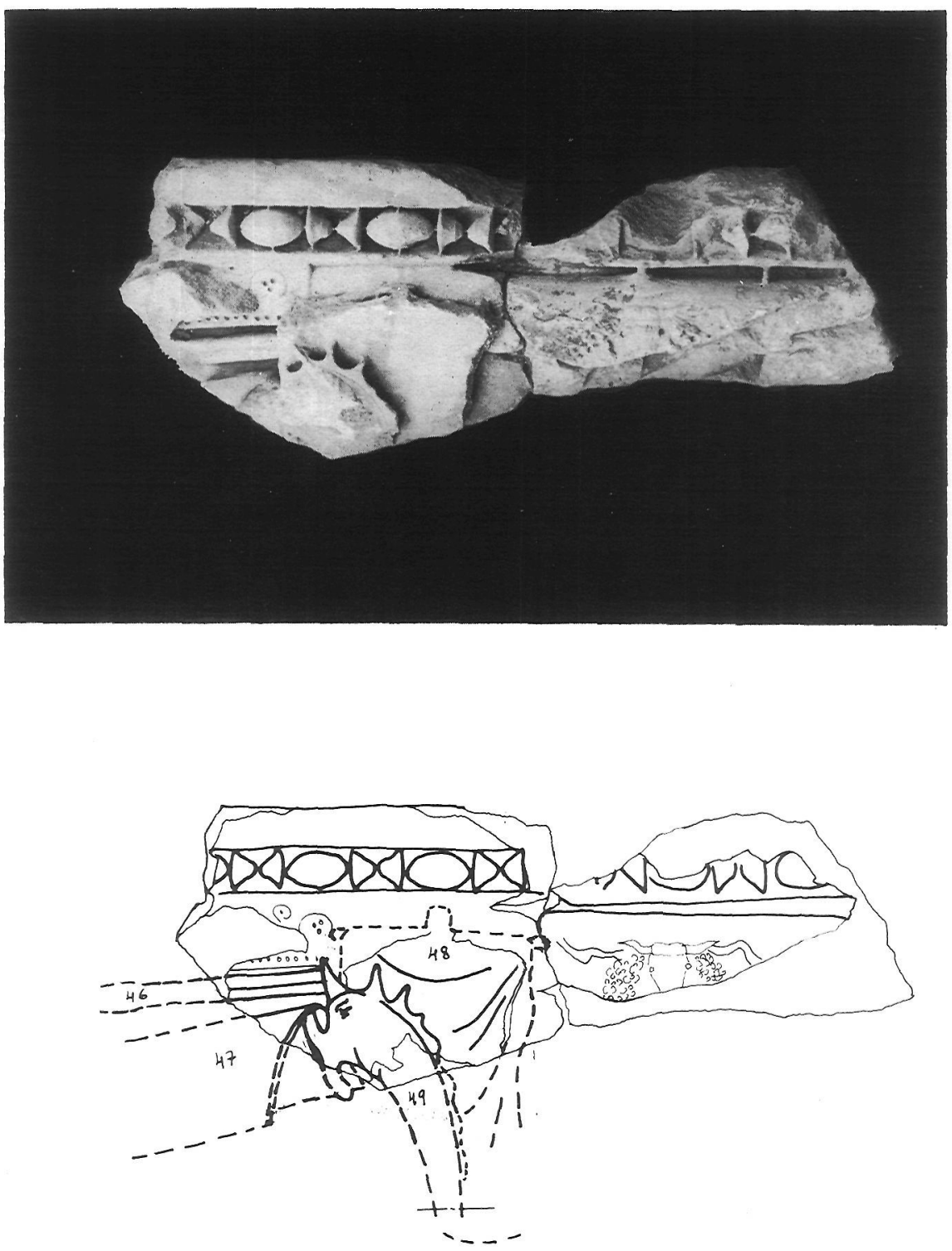

Fragmento núm. $X$. Número 46, mástil geminado de lanza; 47, escudo en forma de teja; 48 , estandarte; 49 , carnyx o trompeta gala. 


\section{Fragmento múm. XI}

Núm. 53.-Zona inferior de un torso thoracato musculado de tipo helenístico carente de lambrequines, sustituidos en este caso por launas o quizá directamente por el colobium. El pliegue inguinal lo constituye una franja decorada con un diseño de olas estilizadas enlazadas. La parte visible del torso se ornamenta con tallos floreados.
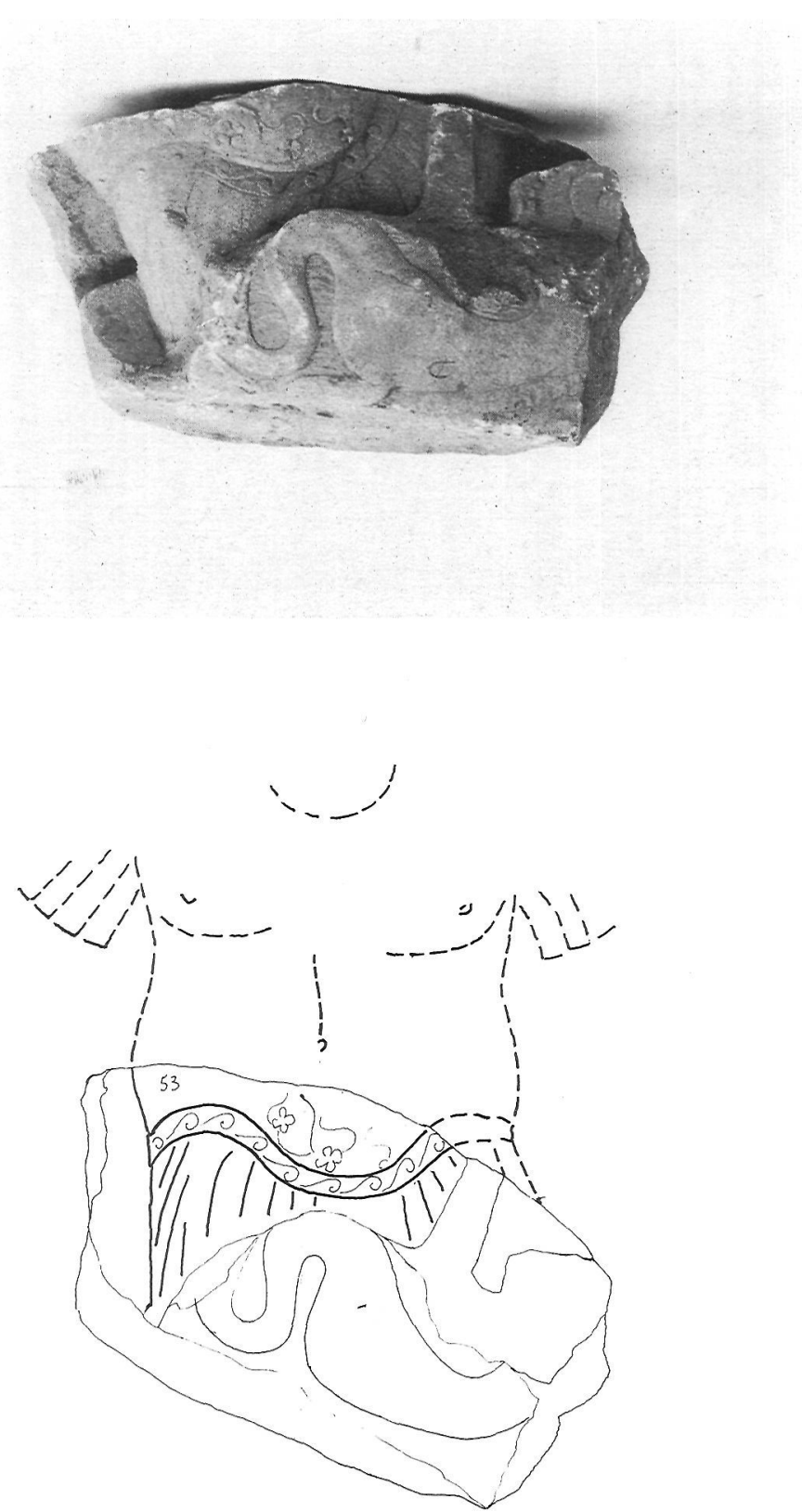

Fragmento núm. XI. Dimensiones: long., 16,3 cms; ancho, $7 \mathrm{cms}$; alto, $9 \mathrm{cms}$. Número 53, parte inferior de una coraza musculada imperial. 


\section{Fragmento núm. XII}

Núm. 50.-Escudo ovalado decorado con roleos y con una escena marina en la que aparecen: un grifo marino, un delfín y un animal serpentiforme, que podría no pertenecer a la decoración propia de la pelta; es muy frecuente encontrar este tipo de animales fantásticos formando parte del repertorio iconográfico que se exhiben en estos temas de armas.
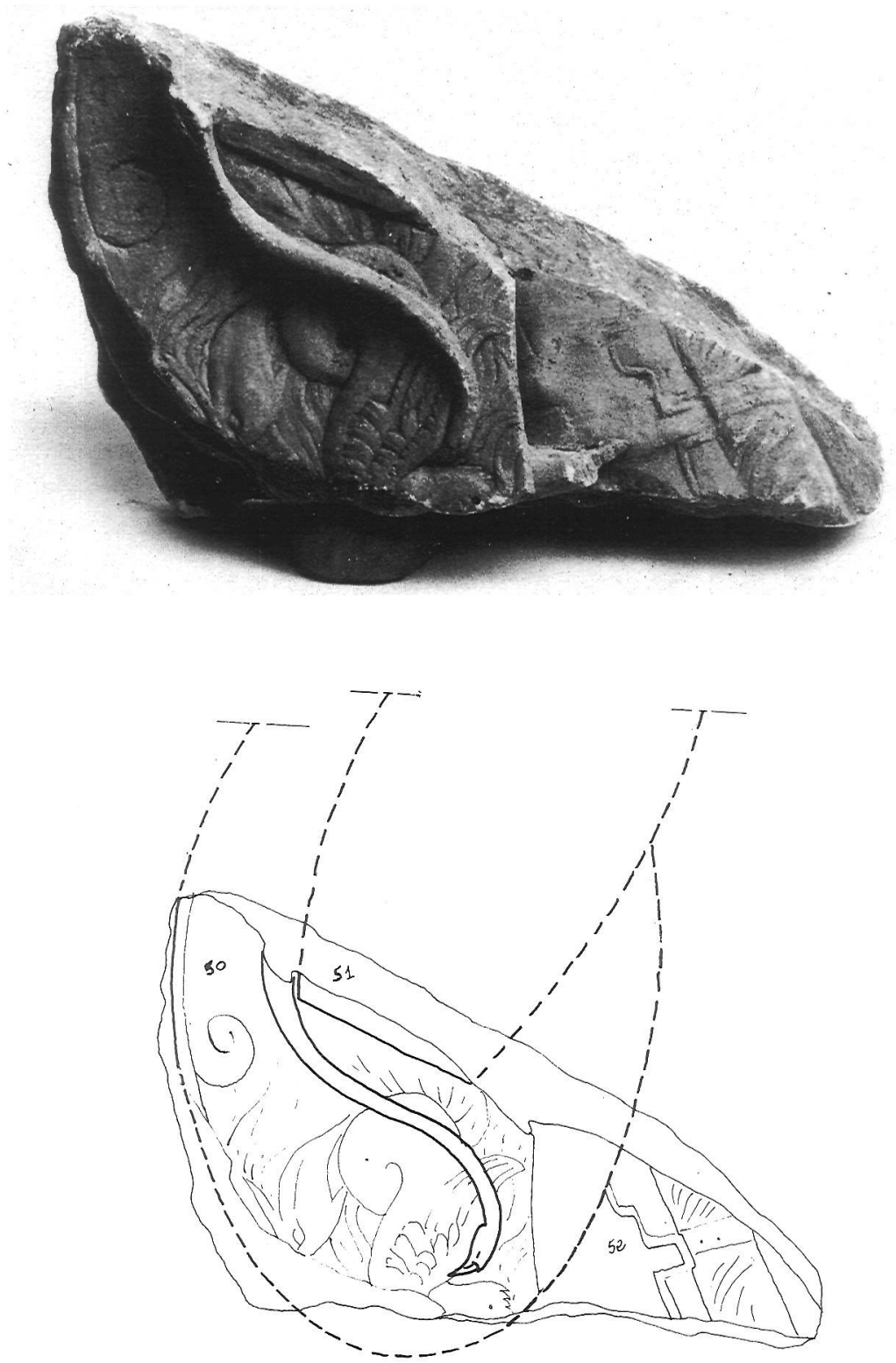

Fragmento núm. XII. Dimensiones: long., $21 \mathrm{cms}$; ancho, 6,5 cms; alto, 10,5 cms. Número 50, escudo ovalado con decoraciones marinas; 51 , base de escudo ovalado de extremos planos; 52 , superficie de un escudo plano. 


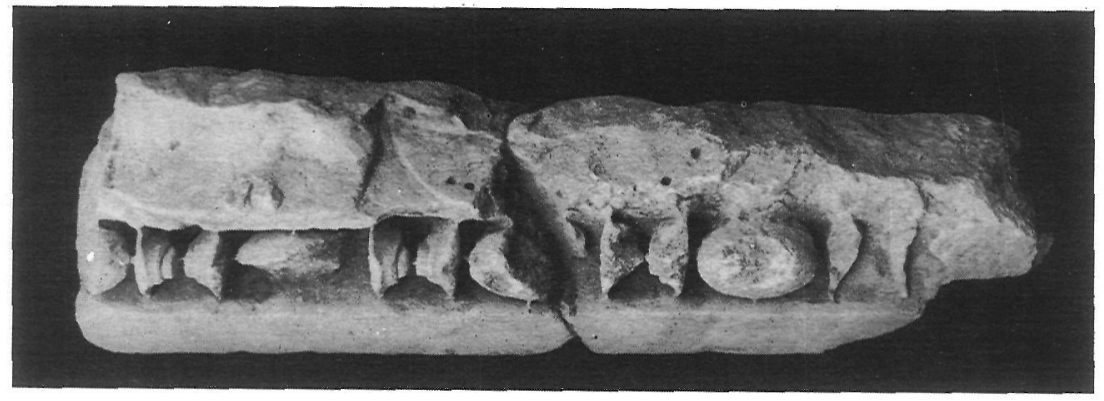

Fragmento núm. XIII. Dimensiones: long., 23,5 cms; ancho, 6,5 cms; alto, $7 \mathrm{cms}$. Restos de bases de escudos.

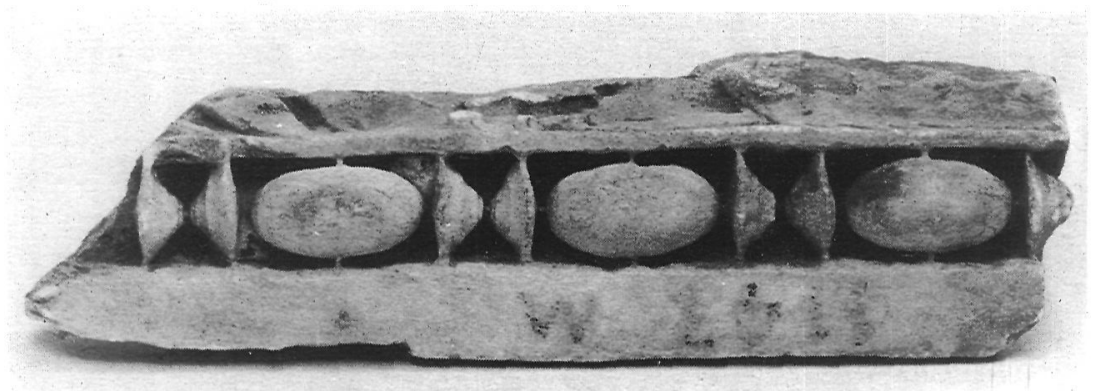

Fragmento núm. XIV. Dimensiones: long., 27,5 cms; ancho, 6,3 cms; alto, 7,3 cms. Restos de bases de escudos.

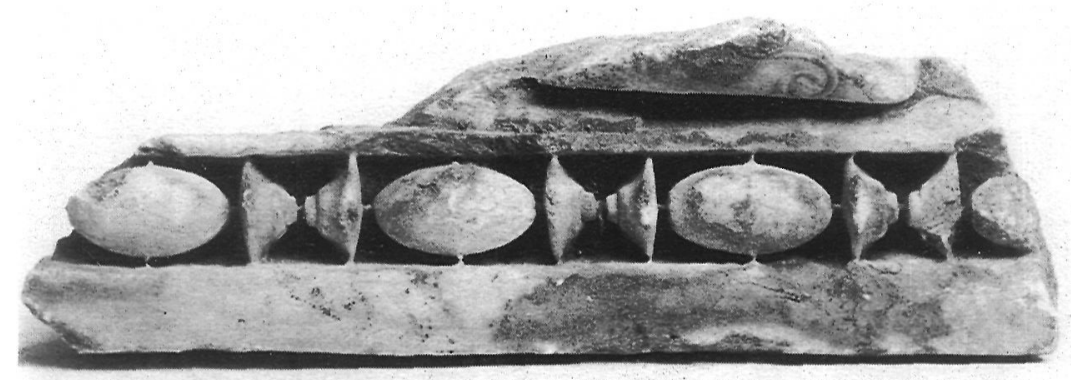

Fragmento núm. $X V$. Dimensiones: long., $21,1 \mathrm{cms}$; ancho, $6 \mathrm{cms}$; alto, 7,5 cms.

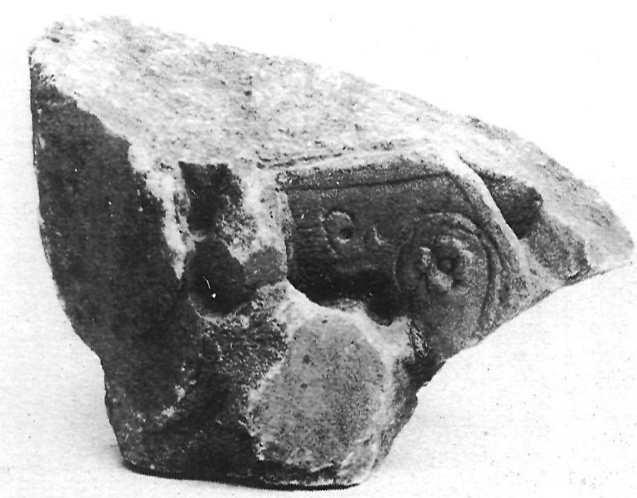

Fragmento núm. XVI. Dimensiones: long., $14 \mathrm{cms}$; ancho, $7 \mathrm{cms}$; alto, $11,5 \mathrm{cms}$. 


\section{COMENTARIOS SOBRE LA MORFOLOGIA DE LAS ARMAS}

Los diferentes tipos de armas que hemos visto representadas en estos relieves responden a un repertorio bastante estereotipado concurrente en la mayoría de los temas que exigen la presencia de armamento. Es una tipología que incluye armas tanto de tipo romano - corazas - como extranjeras - carnyx, peltas-. Una vez más se expresa aquí el espíritu romano, siempre dispuesto a la adopción de elementos no estrictamente suyos, y que comprobamos en las muy diversas manifestaciones de su arte.

\section{LOS ESCUDOS}

Es ésta una de las armas que con más frecuencia vemos representada en los conjuntos de armas amontonadas como en el caso del emeritense.

El escudo hexagonal - arma de antiguo origen galo- hace su aparición en el mundo de la plástica en los monumentos de Pérgamo del siglo III AC. También se usó entre los galos de occidente y más tarde por los germanos. Lo encontramos, por ello, en numerosos monumentos galo-romanos (AMY, DUVAL, ..., 1962; ESPERANDIEU, 1908, 248-249; ESPERANDIEU, 1913, 33).

Se incorporó al ejército romano ya en época de César, cuando éste empleó como tropas de caballería auxiliar a germanos y galos occidentales. En un principio fue usado con exclusividad por estos soldados de caballería, pero en época de Trajano se extenderá su uso a la infantería (COUSSIN, 1926, 395).

El escudo ovalado, aunque preferentemente usado por la caballería, se convirtió en el escudo de la legión por antonomasia. Una variedad de este escudo es el ovalado de extremos planos.

Otro de los escudos que aparece con sorprendente frecuencia en estos relieves emeritenses es la pelta. Fue ésta un arma adoptada por los griegos al entrar los tracios como mercenarios en el ejército helénico. Tradicionalmente y por mediación de los poetas antiguos, la pelta se había considerado un arma amazónica. Como escudo de guerra no parece haber sido usada por el ejército romano, convirtiéndose, sin embargo, en un símbolo que en época imperial llegaría a evocar la virtus del Emperador, por ligar a éste precisamente con aquellos lazos más ancestrales.

\section{LOS CASCOS}

El casco del fragmento número 1 no es uno de los prototipos romanos más característicos como es el caso del tipo de Haguenau, el de Niederbiber o los usuales entre los centuriones y pretorianos (GUSMAN, 1912, pl. 18). Es un casco que se acerca más a los prototipos helénicos que cualquiera de los anteriores a pesar de tener incluso un elemento claramente romano: el penacho.

Un caso verdaderamente original es el del casco de caballería, muy poco frecuente en las representaciones plásticas, en comparación con los otros tipos de cascos. Como ya se ha ilustrado, la mayor parte de los ejemplos con los que contamos corresponden al siglo I d. C.

\section{LAS CORAZAS}

El estudio sistemático de las corazas puede convertirse en una importante fuente de valiosos datos —cronológicos, estilísticos y políticos, fundamentalmente.

$\mathrm{Al}$ abordar el grupo de las corazas imperiales, es decir, las musculadas, nos enfrentamos a una primera dificultad si lo que queremos extraer de ellas es una corriente evo- 
lutiva; tal es el problema de identificación derivado de la falta de correspondencia que se da, en ocasiones, entre los torsos y las cabezas que éstos sustentan.

Un segundo problema es la frecuente carencia de inscripciones u otros elementos acreditativos de una cronología.

Ante estas dificultades, la única posibilidad que nos queda si queremos hacer de un torso un factor cronológico es estudiar por un lado, sus elementos formales y, por otro, los decorativos, tratando de comprobar de esta manera, en qué medida puede trazarse una sistematización.

Aquellos elementos formales susceptibles de aportar datos importantes son:

1.-La posición (torsión del tronco, los brazos, las piernas, la actitud, ...).

2.-La colocación del paludamentum.

3.-El tipo de lambrequines o pteryges.

Secundariamente, otros elementos como el cingulum, el balteus y las launas (3).

Los elementos decorativos que pueden sernos útiles a éstos fines son:

1.-El tema central del torso y de los lambrequines.

2.-La interpretación estilística de dichos temas.

Los cuatro ejemplos de corazas - más o menos fragmentadas - con los que contamos en los relieves emeritenses carecen, en primer lugar, de algunos de los elementos formales sistematizables. El primero de ellos que está ausente es el dato de posición: al no ser estatuas thoracatas propiamente dichas, sólo contamos con que el tronco describe una posición vertical, pero no disponemos de otros indicios como la posición de piernas y brazos, o su actitud. Tampoco contamos con otro de los elementos como el paludamentum $\mathrm{y}$, finalmente, todos los demás están desigualmente repartidos en los cuatro casos con que contamos.

Así pues, si prescindimos de aquellos factores secundarios - inducentes a errorel elemento de mayor crédito que nos queda es el estudio de los lambrequines, y éstos sólo los encontramos en la coraza del fragmento número VI. Veamos pues, antes de analizar este caso, cuál es esa evolución morfológica que se puede observar en los pteryges según la época.

Desde el siglo IV AC en adelante se observa una tendencia en los lambrequines que evoluciona desde una forma plana, larga y rectangular, hacia una mayor semicircularidad. Esta tónica siguió evolucionando ya en época julio-claudia en la que se pueden encontrar pteryges muy largos (thoracato de Nápoles: STEMMER, 1978, Taf. 1-3) o de una longitud mediana (torso de Mentana) STEMMER, 1978, taf. 11-3); pueden también ser más o menos anchos, pero en todos ellos se conserva esa cierta cuadrangularidad heredada de épocas precedentes.

Si ahora observamos, por ejemplo, el torso de Olimpia (STEMMER, 1978, taf. 174) o el de Sabratha (STEMMER, 1978, taf. 38), los lambrequines, en ambos casos, a la vez que poseen una mayor separación entre cada uno y el siguiente, tienden también a una mayor redondez y una menor longitud.

La lista se podría completar suficientemente con algunos ejemplos más de época flavia (STEMMER, 1978, taf: 39-4, 47, 51-5, 52, 55-1) e igualmente otros tantos de la primera mitad del siglo I d. C. (STEMMER, 1978, taf.: $35,36,37, \ldots$ ).

Conviene, no obstante, tener presente que es tan cercana la proximidad de estas dos épocas, que resulta un tanto difícil no encontrar contaminaciones y perduraciones del estilo de hacer julio-claudio en época flavia.

Ya desde fines de época flavia, comprobamos una tendencia - consolidada totalmente en época trajanea- que consiste en acortar los pteryges y darles una forma cada

(3) Véase como catálogos y bases de sistematización: (VERMEULE, 1950 y STEMMER, 1978). Para el caso concreto de España (ACUÑA, 1975). 
vez más semicircular. Tal es el caso del torso del Foro de Trajano (STEMMER, 1978, taf. 45-5 y 6), del de Ostia (STEMMER, 1978, taf. 59-2), Sevilla (STEMMER, 1978, taf. 69), Roma (STEMMER, 1978, taf. 73-1) y Copenhague (STEMMER, 1978, taf. 76).

Pero, a pesar de todos estos datos, existen algunos casos aislados, como antes comentaba, que por su calidad de excepción, aunque no cuestionan la sistematización general, sí obligan a no otorgar a este argumento el carácter de determinante.

Aplicando todas estas premisas a la coraza del fragmento VI de Mérida, comprobaremos que sus lambrequines describen una cierta cuadrangularidad que los haría incluibles en el grupo de los torsos julio-claudios o a lo sumo en los de datación flavia inicial, pero bastante alejados ya de un tipo trajaneo o posterior.

\section{LA DECORACION DE LA CORAZA}

Si pasamos ahora a analizar este otro grupo de datos sistematizables, como son los decorativos, la primera cuestión a tener en cuenta es que, en la medida en que el poder oficial dictamina un programa iconográfico determinado, los temas que se representan en las corazas, pueden ofrecer una secuencia cronológica bastante clarificadora.

Por ejemplo, el tema de los grifos afrontados (fragmento núm. VI), utilizado durante el siglo I y II d. C., desaparecerá ya a partir del año 200 en adelante, después de haber iniciado su decadencia ya desde fines de época de Trajano. Este tema presenta algunas variantes desigualmente repartidas en el tiempo según el estudio de K. Stemmer (STEMMER, 1978, 152 y cuadro). Así, el esquema de los grifos afrontados mediando entre ellos un candelabro, tiene una secuencia ininterrumpida desde Tiberio hasta época antoniniana. Este mismo esquema, pero con las cabezas vueltas hacia atrás, ofrece dos ejemplos, uno con Tiberio y otro con Trajano. Si, por otra parte, el objeto mediador es un tallo con flores o lotos, entonces los casos se ciñen a las épocas de Tiberio y Trajano, fundamentalmente, no constatándose ningún ejemplo para el espacio temporal que media. Paradójicamente, esta misma modalidad, pero con las cabezas mirando hacia atrás, aparece en época julio-claudia, trajanea y domicianea.

Si se reflexiona un poco sobre esto, resulta verdaderamente extraño que el único hecho de tener la cabeza vuelta hacia atrás sea exclusivo de un momento y excluyente de otro que, por otra parte, cuenta con una serie de elementos idénticos e igualmente fundamentales.

Otro estudio encaminado a elaborar una cronología a partir de los datos temáticos ha sido el de C. Delplace (DELPLACE, 1980, 269 ss). Esta vez, sin embargo, el elemento primordial es la fisionomía del grifo. Según su tipología, aquéllos con cabeza leonina y cuernos son los más frecuentes en época julio-claudia, habiendo un resurgimiento en época hadrianea.

Si volvemos ahora a revisar los diferentes catálogos de torsos thoracatos, encontramos que grifos con cabeza leonina conviven con los de cabeza de ave en los diferentes momentos en que vemos desarrollarse este esquema heráldico. Ahora bien, sí parece claro que hay una marcada tendencia a agrupar los de cabeza leonina en la primera mitad del siglo I $\mathrm{d}$. C.

Tomando como ejemplo veintiséis de los torsos del catálogo de Stemmer (4), esta doble variante en la fisionomía del grifo presentará la siguiente proporción:

(4) Esquema general de grifos afrontados. Julio-Claudios: (STEMMER, 1978, pl.: 1-2; 9-3; 17-1, 2 , $3 ; 35-1,3 ; 36-1,3 ; 46 ; 50-1,2$, 3). Flavios: (STEMMER, 1978, pl.: 10-4; 34-2; 50-1; 52; 53; 54). Trajaneos: (STEMMER, 1978, pl.: 10-4; 40-1, 2, 3; 63-1; 76). 
I.-Grifos con cabeza leonina

- Julio-claudios: 10 (STEMMER, 1978, pl.: 1-2; 9-3; 17-1, 2, 3;

$35-1 ; 46 ; 50-1,2,3)$.

- Favios: 3 (STEMMER, 1978, pl.: 10-4; 34-2; 50-1).

- Trajaneos: 5 (STEMMER, 1978, pl.: 40-1, 2, 3; 63-1; 10-4).

II.-Grifos con cabeza de ave

- Julio-claudios: 3 (STEMMER, 1978, pl.: 35-3; 36-1, 3).

- Flavios: 3 (STEMMER, 1978, pl.: 52; 53; 54).

- Trajaneos: 2 (STEMMER, 1978, pl.: 76; 41-1).

Aunque sería un error metodológico abusar de este argumento numérico, convirtiéndolo en base de una conclusión - ya que sólo contamos con una parte de todos los casos posibles-, sí nos puede servir como guía indicadora de una cierta manera de representar.

Un argumento más sólido, en este sentido, lo constituye la morfología de los pteryges que anteriormente he comentado, y más aún el análisis estilístico de la representación de los diferentes temas que pueden aparecer - cuestión que trataré más tarde junto a otros problemas de esta índole.

\section{LA DECORACION DE LAS ARMAS}

Además de la coraza, contamos con otras armas cuyas decoraciones son dignas de interés.

El primer punto a resaltar es el hecho mismo de decorar el armamento con motivos figurativos - componiendo escenas, incluso-. Es éste un caso bastante poco frecuente. La tendencia en la decoración de las armas - especialmente desde fines de época flavia en adelante - es la de plasmación de diseños geometrizantes y abstractos. Baste recordar los escudos del trofeo de Domiciano, las armas de la columna de Trajano, las de la de Marco Aurelio y, en general, las de los monumentos de los siglos III y IV. Pero incluso, cuando encontramos decoración figurativa - pilastras de los Uffizi, trofeos Farnese (DURRY, 1921-22, 303), relieves de Capua (WEGNER, 1961, taf. 54), en todos ellos queda lejana la composición escénica. Según esto, ¿qué puede indicar, entonces, esta manera especial de decorar las armas? Creo que más que un dato cronológico -que sólo podría ser orientativo-, lo que ofrece es un dato de carácter social. No es un simple armamento el que se quiere representar; no es un personaje corriente el que se quiere evocar. Es una alusión directa a un personaje o personajes de un cierto status social y político.

Si analizamos el repertorio de decoraciones que se exhiben, es necesario sentar como premisa que, aunque todas ellas provienen de campos significativos diferentes, han alcanzado ya - tal y como las encontramos en el mundo de la plástica- el estadio de símbolo o alegoría.

Algunas de ellas tienen su génesis en un sentido puramente apotropaico, como los grifos y la gorgona. Un carácter similar tiene el rayo de Júpiter y el águila, que, siendo atributos de este dios, asegurarían la protección del ejército en la batalla; por esta razón fueron adoptados como signos, por antonomasia, de la Legión y del Emperador. Cada legión o cohorte podía adoptar, además, un signo específico, y tal es el caso del león (fragmento núm. II). Este, aunque en un principio cumpliera también un papel mágico, con el tiempo se convirtió en emblema particular de ciertas legiones: la Legio IX Augus- 
ta, la IV Flavia y la XVI Flavia. También fue adoptado junto a la Victoria, al águila y al toro por la Legio V Macedónica; por la XIII Gemina, junto al Capricornio, al águila y a la Victoria y por la Legio XXI Gemina, junto a la Victoria (MAXFIELD, 1981).

Hay, por otra parte, un grupo de decoraciones que no proceden de un ancestral sentido apotropaico, aunque sí de otro de los ámbitos de la religiosidad; concretamente de las ceremonias de culto.

Estas son el bucráneo y el cuerno de carnero.

A.-Bucráneo con guirnalda (fragmento núm. X). Este tema, originalmente ligado al ritual del sacrificio, seguirá apareciendo en multitud de monumentos, sin desprenderse, en la mayor parte de los casos, de su simbolismo religioso. Augusto retomó este motivo iconográfico - al igual que otros muchos de época helenística- haciéndolo representar en numerosas obras artísticas de su tiempo y, entre ellas, en una que -por su significado político y religioso- marcaría una directriz en cuanto a los repertorios iconográficos posteriores: el Ara Pacis.

B.-En el fragmento número III aparece un cuerno de carnero del que pende una guirnalda. Este cuerno puede formar parte de dos figuras: Júpiter Ammón o Aries.

Si nos situamos en el primer caso, hay que recordar que fue Augusto el emperador, por excelencia, que se identificó con Júpiter Ammón. Esta imagen aparece con enorme frecuencia en los monumentos de su época y en los de sus sucesores: los julio-claudios. Pero también conviene tener presente que otro de los emperadores especialmente identificado con Júpiter Ammón fue Domiciano. El ostentaba en la tierra el mismo poder que Júpiter en el cielo, llegando incluso a ser venerado en vida por parte de sus súbditos orientales (SCOTT, 1930, 102).

Esta concepción vigente - con distinta intensidad-durante el siglo I d. C., la encontramos ampliamente documentada arqueológicamente: de época julio-claudia es el altar de Licinius Crasus Fruggi, del Museo Nacional Romano (CANDIDA, 1979, 20-23, tav. VI a); de datación flavia es el ara de P. Ciartus Prepons, también del Museo Nacional Romano (CANDIDA, 1979, 23-25, tav. VII) y la urna de C. Calpurnius Vibianus, del Museo Vaticano (LIPPOLD, 1956, III 2, 211, taf. 99). Si consideramos ahora la posibilidad de que la figura a la que corresponde el cuerno sea la de un carnero - Ariesentonces a quien se está aludiendo directamente es a Minerva: el sol, en el período de Aries, se consagraba a esta diosa. Esta asociación nos traslada de nuevo a la época de Domiciano. Sabemos que este emperador tenía como numen personal a Minerva, y en su honor dedicaba fiestas anuales en la colina albana (SCOTT, 1936, 166 passim), e igualmente gustaba de representarla en numerosas obras artísticas de su tiempo.

En síntesis:-la doble identificación de esta figura - Júpiter Ammón o Aries - nos conduce a la doble posibilidad de evocación de dos personajes: Augusto y Domiciano.

La última de las categorías de decoración figurativa en los relieves emeritenses es la de carácter alegórico.

Una de ellas es la que encontramos en la pelta del fragmento número IV, en la que se representa una escena de ambiente marino. En ella, el protagonista es un tritón acompañado de un delfín.

Conocemos muy bien la relación de estos animales marinos con el mundo funerario, pues su presencia en sarcófagos es muy frecuente (ROBERT, 1969, V 1).

Sin embargo, es evidente que, en un contexto de armas y trofeos, el sentido debe ser otro, relacionado, naturalmente, con el mundo de la guerra. Este significado no puede ser más que el de la victoria sobre los mares.

Contamos para ello con ejemplos muy ilustrativos, como son los monumentos triunfales. En ellos observamos, no obstante, dos tendencias distintas a la hora de plasmar esta concepción. Una de ellas, que podría actuar como denominador común, es la 
de representar una serie de objetos navales: proas, anclas... La otra tendencia -que puede coexistir con la anterior - no es ya tan universal en este tipo de monumentos; tal es la representación de elementos de carácter naturalista (peces, tritones, monstruos marinos). Esta inclinación a lo naturalista es la que se observa de manera especial en aquellas obras más cercanas a la época augustea o próxima (el arco de Orange, por ejemplo).

Así pues, esta escena marina evocaría la victoria sobre los mares siguiendo una tendencia más arraigada en la primera parte del siglo I que en otros momentos; de tratarse así, podría estar aludiendo directamente a una victoria naval que con el tiempo se convirtió en un hecho mítico: Actium.

La última de las decoraciones alegóricas es; sin duda, la más interesante (fragmento núm. I), ya que su significado viene a ratificar de forma definitiva el carácter social y político del relieve en su conjunto.

En esta escena circense, son varios los elementos a considerar. El primero de ellos es la representación misma de una carrera de caballos en el circo.

Este tipo de juegos y celebraciones tiene una larguísima tradición en Roma desde época de los Reyes. Ya entonces se celebraba anualmente un cierto tipo de juegos de los que más tarde derivaron los ludi Maximi o Magni. Paralelamente a estos juegos, había otro tipo de celebraciones cuyo objeto era conmemorar cualquier otro acontecimiento de importancia: tales eran los «Grandes Juegos Votivos». De este último grupo, comenzaron a independizarse a partir del siglo II AC los Juegos Triunfales, cuya celebración podía ser requerida por cualquiera de estos acontecimientos:

- Aniversario de dioses.

- Consagración de estatuas o templos.

- Funerales de difuntos.

- Aniversario de algún personaje ilustre.

- Aniversario y celebración de victorias. (PIGANIOL, 1923, 144).

- Aniversario de la fundación de alguna ciudad.

En época imperial se convirtieron en elementos indispensable para el boato de las celebraciones del triumphus del Emperador.

Además de estos Juegos Triunfales, existía en Roma la costumbre de celebrar juegos antes de cualquier representación teatral o circense: los ludi circenses o scaenici. Estos ludi podían tener lugar como juegos independientes o ligados al conjunto de celebraciones conmemorativas del triumphus.

Parece, pues, bastante claro que la escena circense representada en la pelta, teniendo en cuenta el contexto armamental al que pertenece, alude a estos juegos triunfales ligados a la pompa scaenici.

Otro de los elementos que aparecen en esta escena y que viene a ratificar y ampliar lo que venimos diciendo es la presencia del pileus en la cabeza del putto.

Como se sabe, el pileus era uno de los atributos distintivos de los Dioscuros, quienes, además de estar asociados a la guerra, se convirtieron en protectores de otras muchas actividades: la caza, la navegación y también los espectáculos. Era una costumbre generalizada colocar sus estatuas en el circo.

Esta es, pues, una de las posibilidades de interpretación: la presencia sugerida de los Dioscuros.

Otra posibilidad, sin embargo, es la derivada de la entidad propia del pileus.

El uso de un gorro alto o cónico - de cierto carácter ritual- se remonta a épocas tempranas y a pueblos externos al suelo itálico: orientales y, más tarde, griegos.

Cuando los pueblos itálicos lo adoptaron, hicieron de él -como de otros elementos susceptibles de crear una conciencia de entidad romana - un símbolo sugerente de un pasado lejano y de unas costumbres ancestrales. Con el tiempo el pileus llegó a con- 
vertirse en símbolo de libertad (5). También lo llevarán los esclavos en el momento de su liberación (Liv. XXIV, 32-9).

Naturalmente, la propaganda imperial asoció el pileus al triunfo del Emperador, simbolizando con ello la libertad recuperada o conquistada tras la victoria del general (6).

Este simbolismo particular del pileus sugiere, pues, en el caso del relieve emeritense, más que la evocación a los Dioscuros, la libertad lograda por el triunfo del Emperador; triunfo que, a su vez, se celebra con juegos circenses.

Queda un último elemento: el papel de los putti en esta escena.

El putto es un personaje tradicionalmente ligado a la religión dionisíaca en sus diferentes vertientes, y entre ellas la funeraria, en cuanto garantía de la inmortalidad emanada de su permanente juventud (STUVERAS, 1969).

Pero además de este significado, puede ser simplemente un elemento decorativo, que, por su voluptuosidad de espíritu, aparezca en muy diferentes contextos.

Además de estas dos magnitudes, existe otra relacionada con una parcela más estrictamente romana y que comienza a asentarse de una manera firme a partir de la segunda mitad del siglo I d. C. Tal es la concepción del espacio circense como la representación del Universo entero (HANFMANN, 1951, 159). En esta teoría cosmológica, las estaciones están simbolizadas por cuatro diferentes carros, bridados por putti. Con esto, queda ilustrado, por tanto, que una de las dimensiones espaciales en la que estos personajes podían aparecer era el circo. Queda, no obstante, un poco lejana la posibilidad de que lo que vemos representado sea una estación: en primer lugar, son sólo dos caballos - no un carro-; en segundo lugar, de constituir una estación, quedaría entonces excluida la datación de la primera mitad del siglo I d.C.

\section{LA DECORACION NO FIGURATIVA}

La mayoría de los motivos ornamentales que representan los relieves emeritenses son los mismos que inundan la mayor parte de las manifestaciones artísticas del mundo romano y cuyo origen hay que buscar en el arte helenístico. Algunos de ellos, sin embargo, serán retomados en época romana, adquiriendo un simbolismo nuevo. Esto ocurre, por ejemplo, con la decoración vegetal, que, profusamente utilizada en el Ara Pacis, se convertirá en signo evocador de la «prosperidad augustea». Pero, mientras que esta decoración no pasó de ser un signo - en gran parte inconsciente- aplicado a contextos de muy distinto tipo, otro motivo vegetal - la corona de roble - sustentó una simbología muy concreta y definida.

La corona quercea o corona «cívica» (fragmentos núms. I y II) se otorgaba tradicionalmente y con carácter vitalicio al hombre que en batalla había salvado la vida a un ciudadano romano o había dado muerte a un enemigo. Fue progresivamente adquiriendo relevancia sobre otras coronas - obsidionalis, muralis, vallaris... - hasta convertirse en el símbolo del poder imperial por antonomasia (MAXFIELD, 1981, 67).

\section{El contario «canónico»}

Es éste otro de los elementos decorativos que vemos enmarca varios de los frag-

(5) Lo vemos en algunas monedas como atributo de Libertas; monedas de Galba: (MATTINGLY y SYDENHAM, 1923, vol. I, p. 200, pl. XIII-225). Monedas de Cómodo: (MATTINGLY y SYDENHAM, vol. III, 1968, 381 passim, núm. 135). Monedas de Nerva: (BLANCHET, 1895, núm. 5, pl. III-3).

(6) (LIV. XXX, 45.5: Hunc regem in triumpho ductum polybius, scipio nem triumphantem est pilleo capiti imposito $Q$. terentius Culleo, omnique deinde vita, ut dignum erat, libertatis auctorem coluit). 
mentos, sirviendo además de importante apoyo a algunos de los autores que nombrábamos al principio, al definir la cronología del conjunto.

El contario de perlas u ovas y carretes es uno de los elementos más profusamente utilizados en la decoración arquitectónica romana. Si bien es cierto que este diseño manifiesta tendencias formales diferentes según las épocas (7), muestra también una serie de irregularidades, en este sentido, que imposibilita su uso como patrón cronológico. Una de estas irregularidades es, por ejemplo, el que un determinado diseño de esta decoración aparezca en monumentos distintos en estilo y datación: templo de Venus Genetrix y arco de Tito (WEGNER, 1957, 48-49). Lo mismo ocurre entre monumentos más alejados en el tiempo: templo de la Concordia - augusteo-y un fragmento de entablamento del Foro de Trajano (WEGNER, 1957, 48-49).

También encontramos el caso inverso: que en un mismo monumento coexistan dos tipos diferentes de contario; así ocurre en el arco de Tito y en el arco de Orange.

$\mathrm{Si}$, de todas formas y como último recurso, decidiéramos paralelizar el diseño de los fragmentos emeritenses con los de otros monumentos, el caso más cercano lo encontraríamos en el Foro de Nerva, y aunque también lo observamos en otros monumentos de datación flavia - trofeos Farnese (DURRY, 1921-23, 303) - no lo poseen, sin embargo, otros ejemplos de esta cronología, emergentes de círculos artísticos oficiales, como el arco de Tito. Lo problemático de éste no se acaba ahí, sino que la existencia de ese mismo diseño, que vemos en estos monumentos flavios y en los relieves emeritenses, es comprobable también en un prototipo de cronología tiberiana: el arco de Orange. (AMY, DUVAL..., 1962, pl. 66, 67, 68 a, 70 a, 72 a y b, 83, 90 c y d, 92).

Con todos estos problemas, es evidente que el contario no puede constituir el argumento principal y determinante de una cronología, tan sólo, en todo caso, una orientación aproximativa y revisable en cualquier momento.

Sintetizando todos los datos obtenidos del análisis de los fragmentos, los podríamos agrupar según el tipo de información que ofrecen:

\section{Datos de tipo político-social}

- Desde un punto de vista morfológico, las armas que se han representado pertenecen fundamentalmente a cuerpos de alto status en el ejército: caballería auxiliar, altos oficiales de la Legión...

- La alta proporción de decoración figurativa sugiere la evocación o la dedicación del conjunto a un personaje o personajes de rango relevante.

- Este personaje no es otro que el Emperador, cuyos signos visibles son:

- La «corona cívica».

- Las peltas - símbolo de la virtus imperial.

- El tipo de decoraciones de las corazas del fragmento VI y VII. - Lo que de manera especial se evoca del emperador es el triunfo, simbolizado en:

- Escena de ludi triunfales.

- Pileus como símbolo de la libertad conquistada por el triunfo.

- La Victoria, llevando también la «corona cívica».

- La escena marina, que alegoriza el triunfo sobre los mares -quizás Actium-.

(7) Los contarios canónicos que aparecen desde Septimio Severo en adelante muestran, en general, una tendencia más angulosa y geometrizante (WEGNER, 1957, 48 y 49). 


\section{Datos de tipo cronológico}

- El león del escudo: insignia de varias legiones creadas a lo largo del siglo I de J. C.

- Los lambrequines de la coraza número VII siguen una morfología parangonable a los de fines de época julio-claudia.

- El tema de los grifos afrontados con cabeza leonina y cuernos es especialmente frecuente en época julio-claudia, aunque sin excluir momentos posteriores.

- El tema de Júpiter Ammón o de Aries, aun representándose en épocas diferentes, posee una mayor relevancia durante el siglo I de J. C.

- La representación del águila con las alas tiende a desarrollarse de manera especial en tiempos julio-claudios (relieve de los Pretorianos, Gema Augustea).

- Las decoraciones de las armas con motivos figurativos van desapareciendo a partir del siglo I de J. C. o de comienzos del siglo II.

\section{CONSIDERACIONES ESTILISTICAS Y CRONOLOGIA}

Se puede observar fácilmente que algunos de los temas que antes comentábamos - grifos, gorgonas, águilas...- los encontramos ampliamente repartidos como tema iconográfico a lo largo de distintos momentos. Una primera selección temporal puede constituir el lenguaje formal en que estos temas han sido expresados (el águila con las alas plegadas). Si, además, pretendemos una mayor precisión, habrá que recurrir entonces a otra fuente de información: la plasmación plástica de esos temas. Es éste un aspecto que puede dar la última palabra en materia cronológica cuando carecemos de otros elementos más definitorios como inscripciones y datos estratigráficos.

Para abordar el análisis estilístico de las representaciones de estos relieves emeritenses, tomaremos como punto de partida la asignación histórico-artística y cronológica que les dieron los diversos autores ya mencionados anteriormente (ver pág. 2). Los apoyos fundamentales en los que Wegner, P. León, Blanco y Traversari basaron su datación fueron de dos tipos: por una parte, el contario «canónico» que acabamos de analizar; por otra, la identificación de una serie de atributos estilísticos como la «plástica colorística del barroco flavio" (8).

Si bien, en sentido genérico, se puede hablar de estas cualidades como inmanentes al «barroco» flavio, estos conceptos son lo suficientemente ambiguos y subjetivos como para no constituir una razón firme, si no se presentan a su lado las pruebas que los avalen.

Cuando se trata de clasificar una obra siguiendo criterios estilísticos, es necesario entrar en el análisis de sus elementos estructurales, por una parte, y de sus elementos formales, por otra. Quizás, y sólo así, podremos respaldar atributos tan amplios como los anteriores, utilizados para definir brevemente una corriente artística.

Si comenzamos, entonces, por estudiar la estructura compositiva de algunas obras fechadas como flavias - los relieves de Capua o los de la Domus Flavia-, observaremos, en primer lugar, que la descomposición del conjunto en sus diferentes planos de

(8) TRAVERSARI, 1971, 76: «... e forse un rilievo nel Museo di Merida, che supera i primi due per l'accuratezza e la finezza del disegno, in particolare degli scudi, degli elmi, dei foderi delle spade; tutti e tre comunque mostrano, nell'infitimento delle armi, nel loro incrociarsi e sovrapporsi, gli accenti pesantemente plastico-coloristici del barocco flavio, ampolloso, retorico nella sua piú dinamica espresione». 
profundidad se presenta como tarea difícil. Esa dificultosa aprehensión provocada por un ritmo violento no obedece a otra causa más que al juego de diagonales y angulosidades que siguen los planos entre sí.

Aparte de estos elementos estructurales que contribuyen desde la perspectiva compositiva a la formación de un conjunto barroco, existe otro grupo de elementos sobre los que descansan y encuentran justificación las impresiones de plasticidad y colorismo y que - según algunos autores - son los que determinan, en última instancia, el sello de un estilo: tal es la plástica que conforma el detalle.

Observemos algunos de los ejemplos más característicos en este sentido, como la urna de los Platorinos (GUSMAN, 1912, pl. 75) o la de C. Calpurnius Vibianus (LIPPOLD, 1956, III 2, 211, taf. 99) y comparémoslas con el cipo sepulcral de Amemptus, del Museo del Louvre (GUSMAN, 1912, pl. 78) u otras de datación julio-claudia (GUSMAN, 1912, pl. 70).

Los contrastes de luz y sombra -más fuertes en las urnas flavias- son en definitiva un efecto logrado por la conjunción de dos elementos: una cierta altura del relieve y una mayor definición de los volúmenes. Las figuras circundantes al eje principal conservan, aun siendo prácticamente planas, esa cierta altura que permite adivinar los rasgos de los volúmenes y, por tanto, la captación más unitaria del conjunto.

En el caso de las julio-claudias, la altura del relieve de las figuras centrales -que puede ser incluso igual a la de las flavias - tiende a degradarse conforme se avanza hacia las figuras periféricas, de las que casi sólo se llega a definir el contorno lineal.

Ese afán del estilo flavio por definir los volúmenes - la «plasticidad»- no entra en contradicción con esa otra característica que le es tan propia -el ilusionismo-. Esa captación casi velazqueña de la atmósfera que vemos en el arco de Tito o en la tumba de los Haterios, no precisa necesariamente de la anulación de las formas; a lo que se recurre en este caso es al difuminado de los detalles particulares.

Resumiendo todas estas ideas, el barroco flavio se sustentaría estructuralmente en el ritmo y el juego de los diferentes planos de profundidad; formalmente, en la combinación de un cierto altorrelieve, de la definición absoluta de los volúmenes y de la veladura de los detalles más minuciosos.

Se puede ahora comprobar en qué medida los relieves emeritenses se hacen eco de esta corriente. Antes, sin embargo, es necesario plantear una cuestión básica: la alineación de estas piezas en la estilística oficial o en la versión provincial de los temas iconográficos del arte áulico.

En primer lugar, baste comparar este conjunto con otros considerados provinciales y fechados a mediados del siglo I de J. C.: los relieves de Clunia. A simple vista se aprecia el enorme abismo estilístico entre ambos casos. En segundo lugar - y esto viene a ratificar el punto anterior - hay que considerar el contexto en que aparecieron: un ambiente arqueológico con multitud de testimonios del culto, la política y el arte oficial.

Creo, por fin, que las piezas emeritenses pueden encuadrarse dentro de la corriente oficial y urbana del arte romano.

Partiendo de este punto, podemos comenzar a comparar la estructura compositiva de las piezas emeritenses con las de la Domus Flavia o la de Capua. El movimiento en estas últimas supera con mucho al de las de Mérida, que consiste, fundamentalmente, en un esquema de cuatro planos de marcado paralelismo, si se compara con la oblicuidad de aquéllas. Perceptivamente los emeritenses son más abarcables y los encontramos más próximos a las armoniosas composiciones augusteas o julio-claudias.

Otro de los elementos estructurales presentes en los relieves de Mérida es el abigarramiento de figuras. Es éste un componente que puede o no provocar un efecto barroquizante según se combine con otro tipo de elementos, como el ritmo de los planos, y, de manera especial, con la plástica formal en que estén concebidas las figuras. 
Prueba de que abigarramiento de figuras y barroquismo no son sinónimos es el caso de la base de la columna de Trajano (La colonna Traiana, 1942, núm. 1 a 7 ). En ella, el tema de las armas amontonadas presenta una planitud que la aleja del calificativo de «barroca». Los elementos que aquí han intervenido son: un enorme espacio para el desarrollo de dos únicos planos que además se superponen casi de forma paralela, y un relieve de escasa altura en los objetos representados.

En sentido inverso, tenemos otro ejemplo ilustrativo en uno de los cipos sepulcrales de datación julio-claudia del Museo del Louvre (GUSMAN, 1912, pl. 70). En él, la multitud de figuras se mueven prácticamente en un único plano - exento, por tanto, de ritmo- y, sin embargo, el efecto es de un barroquismo exuberante. La razón no está tanto en problemas compositivos como en la labor formal de cada objeto (relieves altos en las partes centrales y multitud de pequeños elementos que se diseminan y esparcen sobre el fondo neutro de la composición).

El calificativo «barroco» no es - como se comprueba- exclusivo del estilo flavio. Por esta misma razón, aunque los relieves de Mérida contengan algo de barroquismo, no necesariamente han de ser flavios.

Analizando ahora la labor de detalle o plástica formal a la que nos referíamos, podríamos sintetizarla en los fragmentos emeritenses en base a dos categorías: la plástica de cada objeto individual y la de las decoraciones que cada uno de ellos ostente.

Sobre el primero de los puntos, observamos, en primer lugar, que las armas u otros objetos no poseen una altura comparable a las de las piezas flavias anteriormente comentadas -es un relieve bastante más bajo-. En segundo lugar, los diferentes cuerpos, aunque mantienen sus volúmenes y entidades plásticas bien definidas, no llegan, en algunos casos, a alcanzar esa perfecta disociación entre unos y otros: en el fragmento número II, sorprende, por ejemplo, que la carrillera del casco parece salir del costado de la coraza como si estuviera incrustada en ella, creando así el efecto de un falso realismo.

En cuanto al segundo punto - la labor de detalle manifestada a traves de las decoraciones de las armas-, conviene establecer una serie de categorías según los puntos clave para la definición de este tipo de labor:

\section{I.-Los volúmenes}

En general, los motivos decorativos están bastante definidos, salvo en algunos casos de la decoración vegetal. Por ejemplo, en el fragmento número III, en el que algunos roleos muestran su contorno lineal simplemente dibujado.

\section{II.-Altura del relieve}

Es bastante bajo si se compara con otros prototipos de época flavia. Muy clarificadora a este respecto puede ser la comparación con una pieza de pequeño tamaño - partícipe, por tanto, de las mismas coordenadas espaciales que las emeritenses-, como es la decoración sobre un lambrequín. Este reducido espacio puede albergar un relieve muy alto como en el caso del torso de Sabratha (STEMMER, 1978, pl. 38) o el torso del Louvre (STEMMER, 1978, pl. 53), ambos de datación flavia. Una pteryge puede, por el contrario, presentar un relieve bajo: thoracato de la Glyptoteca de Munich (STEMMER, 1978, taf. 46) o el de Nápoles (STEMMER, 1978, taf. 35-2).

\section{III._Dibujado o veladura de los detalles}

De una manera especialmente minuciosa se han plasmado los siguientes detalles:

- Nervaduras y detalles de la decoración vegetal, aunque en una ejecución algo ya alejada del exacerbado naturalismo augusteo. 
- Las olas marinas (fragmento IV), los cabellos sueltos de la Gorgona (fragmentos II y VI), el pelaje del león (fragmento II), las plumas del águila (fragmento III), las alas de los grifos (fragmento VII), la anatomía de los caballos (fragmento I) y otros detalles, se han plasmado de tal manera que los ejemplos más próximos los encontramos en obras de cronología julio-claudia: relieve del Museo de Vienne (BIANCHI BANDINELLI, 1969, 192, f. 206) o el del Museo Barberiniano de Palestrina (BIANCHI BANDINELLI, 1969, 193, f. 207), por citar algunos entre las numerosas obras de esta datación que participan de estas características.

\section{IV.-La labor de trépano}

En los relieves de Mérida se ha llevado a cabo un doble trabajo en este sentido. Uno de éstos es el que consiste en la trepanación de forma continua - a base de pequeños y desordenados orificios - y cuyo resultado es un volumen amorfo y de difícil identificación. Tal es el caso de las guirnaldas (fragmentos III y X) y el ángulo visible del panel de artillería (fragmento III). Esta labor en las guirnaldas la comprobamos también en las piezas naturalistas que acabamos de citar. Cuando en época flavia o posterior encontramos esta forma de trepanación, se constata, no obstante, que el efecto no es el de la amorfización de los cuerpos, sino que tiende a respetar las líneas definitorias.

El otro tipo de labor de trépano es el que produce la impresión de «tela bordada» al intentar separar unos objetos de otros. La encontramos especialmente patente en las crines de los caballos (fragmento I) y en las coronas «ć́vicas» (fragmentos I y III).

Los ejemplos ilustrativos de este tipo de labor han sido fechados hacia la mitad del siglo I d. C. Tales son:

- Altar de Accia Pelagia (CANDIDA, 1979, 16, tav. IV).

- Altar de T. Apusulenus Caerellianus (CANDIDA, 1979, 28, tav. IX).

- Altar de M. Valerius Saturninus (CANDIDA, 1979, 48, tav. XVIII 18).

- Altar de Aurelia Nais (CANDIDA, 1979, 132, tav. XLVII-59 b).

- Tumba de Laberia Felicia (GUSMAN, 1912, pl. 100).

Como se desprende de lo expuesto hasta aquí, es difícil asignar una cronología precisa a los relieves emeritenses. Tanto los temas representados en las armas como el lenguaje formal en que han sido expresados apuntan claramente hacia el siglo I d. C., y en especial la primera mitad, aunque no podamos excluir la segunda mitad o incluso los comienzos de época trajanea.

Sin embargo, sí contamos con otros apoyos susceptibles de ofrecer una mayor precisión, como son:

- El análisis de los lambrequines de la coraza (fragmento VII), que sugiere una época julio-claudia avanzada.

- El análisis estilístico. Según la estructura, serían fechables hacia mediados del siglo I de J. C. Según el detalle -que es lo que determina, en definitiva - queda excluida la época trajanea y hadrianea.

También se encuentran algo alejados del naturalismo augusteo, pero sí próximos a él, un naturalismo que difícilmente comprobamos en tiempos flavios.

Todos estos indicios apuntan, pues, a un momento avanzado de la dinastía julioclaudia, en el que se comienzan a vislumbrar rasgos de la expresión artística flavia. 


\section{HALLAZGO Y LOCALIZACION DE LOS RELIEVES}

Durante las campañas de excavación de los años 1929 y 1931, Mélida y Macías (MELIDA y MACIAS, 1932, 13) llevaron a cabo el estudio arqueológico de la postescena del teatro, que pronto reconocieron como un peristilo. En el fondo del conjunto y formando parte del mismo eje de la valva regia, apareció un ambiente arqueológico que más tarde, en 1944, Floriano definió como una escuela o una biblioteca. Fue allí mismo o en un punto próximo donde se descubrió el conjunto de fragmentos que aquí se estudian (desconocemos el número exacto que apareció).

La identificación de dicho ambiente con una biblioteca encontraría apoyo en la aparición misma de varias estatuas de togados y en la existencia de cuatro nichos en las paredes, donde supuestamente irían colocadas las cistae con los rollos escritos. Las cabezas marmóreas de Augusto y Tiberio, en este contexto, indicarían — sin la menor extrañeza- la presencia de la propaganda imperial en un recinto cultural como aquel.

Si consideramos, por otra parte, la posibilidad de definir la estancia como una schola, conviene recordar, en primer lugar, que este término ha tenido diferentes sentidos según el momento.

Genéricamente una schola es un lugar destinado a la reunión de los collegia funeraticia o, de forma coyuntural, del Senado (como fue el caso del pórtico de Octavio). Podía servir también, simplemente, como lugar público en el que los transeúntes detendrían su paso para conversar ( $D S$, s. v. Schola, Cagnat, p. 1.120).

Este tipo de estancias, generalmente circulares, se revestían con mármoles de colores y solían albergar estatuas de célebres personajes.

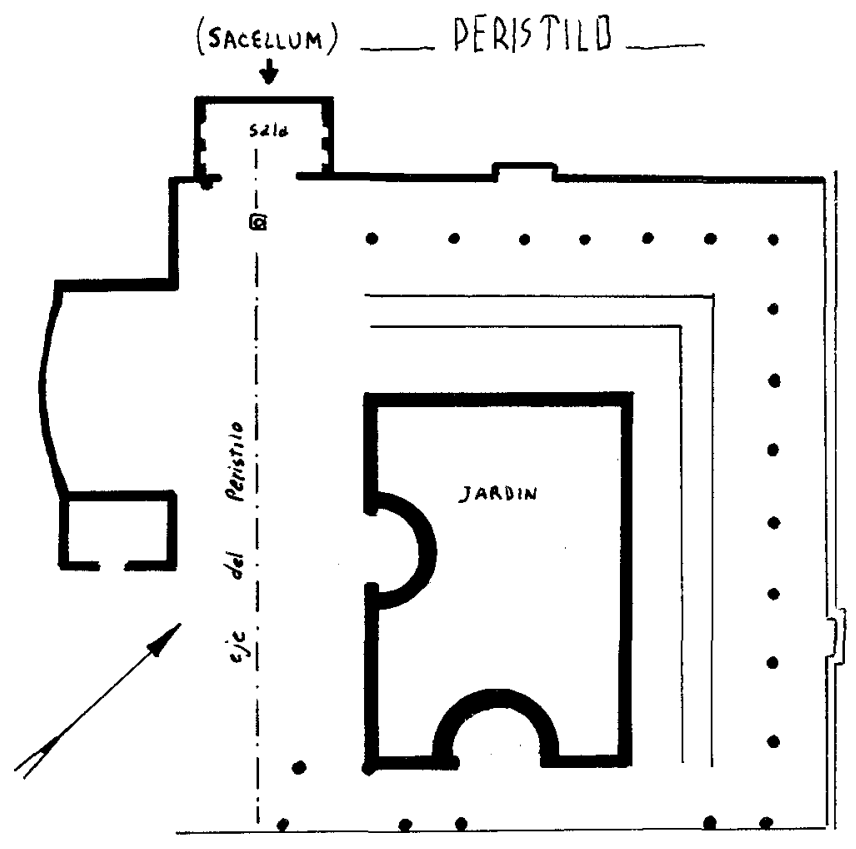

Extracto del plano realizado por Antonio Floriano como resultado de las campañas de excavación en la zona del peristilo entre los años 1934 a 1936 (FLORIANO, 1944, p. 154, f. 1). En él hemos señalado lo que definimos como sacellum. 
En este pequeño recinto emeritense, además de las piezas arriba mencionadas, se encontraron numerosos restos relativos al culto y a la política imperial: las lápidas de los hijos de Agrippa (MELIDA, 1925, núm. 762), la herma del primer gobernador de Lusitania (MELIDA, 1925, núm. 779 y núm. 902), un epígrafe dedicado a Tiberio por la colonia (MELIDA, 1925, núm. 77) la tabula de amistad entre emeritenses y uguienses (ALVAREZ SAENZ DE BURUAGA, 1980), el grupo de Pan y Panisco (MELIDA, 1.925, núm. 1102), un clípeo de Júpiter Ammón (MELIDA, 1925, núm. 1.110) y una ocrea de bronce de algún trofeo militar del tipo «Ipona» (ACUÑA, 1975, 122).

Todos estos objetos, como decía, indican una relación tan estrecha con la política y el culto imperial que, sin rechazar la identificación de la estancia con una schola o una biblioteca, nos llevan a considerar otra posibilidad que el señor Saenz de Buruaga (SAENZ DE BURUAGA, 1980) y el doctor Alvarez Martínez (ALVAREZ MARTINEZ, 1981, 254) ya han planteado; tal es que el recinto pueda considerarse como un sacellum dedicado al culto imperial.

La presencia de recintos culturales - bien se trate de templos o de sacella- es prácticamente universal en los teatros del imperio Romano.

El teatro mismo, en su lugar de nacimiento - Grecia - tenía un profundo sentido religioso; sentido que Roma supo captar y a la vez enriquecer con la anexión de elementos enraizados en su propia cultura y con la creación de un ceremonial típicamente romano.

Son numerosos los ejemplos de templos que encontramos situados en diferentes puntos de área teatral. El caso más frecuente es el de los que forman parte del ámbito de la cavea - los «cavea shrines» como los denomina Hanson (HANSON, 1959, 81-92). Dentro de este grupo, los teatros de Leptis Magna (CAPUTO, 1950, 169-174. f. 1-3); (HANSON, 1959, 59 f. 22), Tipasa (FREZOULS, 1952, 111-177), (HANSON, 1959, 66); Sagunto (PUIG y CADAFALCH, 1934, 196-201, f. 254), Apamea (MAYENCE, 1939, 206-208) y Herculano (HANSON, 1959, 74-75, f. 41), poseen recintos culturales situados en la summa cavea y en los que el muro posterior de la cella coincide con el muro de fondo de la summa cavea.

En los teatros de Lillebonne (WIESELER, 1851, 21-22, pl. II), (HANSON, 1959, 69 , f. 34) y de Pausilypon (HANSON, 1959, 74-75, f. 39), el templete está inscrito en la ima cavea. En Calama (HANSON, 1959, 62-77, f. 25), Philippeville (GSELL, 1901, 192-194 f. 63), (HANSON, 1959, 62, f. 26), Cherchel (GSELL, 1901, 104-108), (HANSON, 1959, 64, f. 28), Vienne (HANSON, 1959, 68, f. 32), (FORMIGE, 1950, 9-11, f. 30), Vaison (HANSON, 1959, 70) y Casinum (HANSON, 1959, 73-74, f. 77), sólo parte del templo está en contacto con la cavea. Finalmente, otros templos se construyen totalmente fuera del área de la cavea, pero manteniéndose adosados a ella por la parte de la fachada exterior: tal es el caso del teatro de Pompeyo en Roma (HANSON, 1959, 48 y 53-55, f. 19), Dugga (CARTON, 1902, 145-156, pl. 11-15), Timgad (GSELL, 1901, 197199), (CAPUTO, 1950, 171; IDEM, 1947, 19), Nicopolis (HANSON, 1959, 71, 36), Sepino (CIANFARANI, 1951, 88-106, pl. 88) y Villa Hadrianea (HANSON, 1959, 72, f. 37 y 38 ).

Además de estos templos de cavea, existe otro grupo que se localiza en la postscae$n a$, formando parte del pórtico y, muy a menudo, en el mismo eje de la valva regia y del otro posible templo de cavea. Este es el caso de Leptis Magna (HANSON, 1959, 95; CAPUTO, 1950, 166-167) y de Ostia (HANSON, 1959, 95, f. 45). Algunos de estos recintos culturales de los pórticos de la postscaena podían estar dedicados a los cultos dinásticos, como en el caso de Leptis Magna, donde existía un santuario consagrado a los Dii Augusti. Este mismo caso lo comprobamos en el teatro de Cherchel (HANSON, 1959, 64-65, 77, f. 28) y en el de Bulla Regia (PICARD, 1975, 395). 
Estos sacella - de planta rectangular, generalmente- se construían, en ocasiones, como en el caso del teatro de Stobi (SARIA, 1938, cols. 106-116, 135-144), a un nivel más bajo que el resto del recinto.

A la vista de todo esto, la estancia emeritense podría perfectamente definirse como un sacellum dedicado al culto imperial, sobre todo si se tiene presente la cantidad de testimonios arqueológicos allí encontrados, y que avalan esta posibilidad.

La mayoría de éstos se refieren a la familia augustea o a personajes políticos importantes de esa misma época. La construcción, por tanto, debió llevarse a cabo simultáneamente a la construcción del teatro o pocos años después.

La función que este sacellum desempeñaría en el contexto del teatro iría íntimamente relacionada con el desarrollo de la pompa scaenici.

Aunque apenas se conocen testimonios del tipo de ceremonias que se llevaban a cabo en los ya mencionados ludi scaenici, según cuenta Tertuliano, estas celebraciones eran iguales a las de los ludi circenses (9). Esta pompa consistía en un desfile procesional que discurría por el peristilo del teatro y tenía como fin el sacrificio en un altar emplazado en la orchestra o en el pulpitum (HANSON, 1959, 81 passim).

En Mérida se han encontrado cuatro altares: uno de ellos en la orchestra y los otros tres en sendos nichos del pulpitum. Allí tendrían lugar diversos sacrificios en honor de los dioses representados en la frons scaenae.

El papel del sacellum en todo esto sería el de lugar de parada del cortejo, en la que los flamines realizarían libaciones en honor a los emperadores divinizados de la familia de Augusto y de sus sucesores.

La existencia de una ceremonia institucionalizada como ésta, guarda una perfecta relación con el tipo de ciudad que era Mérida.

De todos es conocido que la razón fundamental que movió a Augusto y Agripa, a través de $\mathrm{P}$. Carisio, a la fundación de Mérida no fue únicamente el deseo de dar a los veteranos de las legiones V y X un lugar agradable donde vivir. La verdadera razón - la política - era la posibilidad de que una ciudad de las características estratégicas de Mérida controlara todo un territorio en el que aún quedaba mucho por romanizar.

Por ello se convirtió en la capital de la Lusitania y bajo su dominio se colocaron, además de otras cuatro colonias de la provincia -Scalabis, Olisipo, Pax Iulia y Helmantica-, medio centenar de poblaciones y numerosas tribus indígenas (ALVAREZ SAENZ DE BURUAGA, 1976, 19 y passim).

Se convirtió en una ciudad cuyo índice de población era superior al de otra ciudad cualquiera de la península (FORNI, 1982,69 passim). Sus dominios territoriales se prolongaban en decenas de kilómetros, y en ella misma se cruzaban ocho importantes vías, entre ellas, la de la Plata (CORZO, 1976, 217 passim).

Roma se propuso hacer de Mérida una ciudad floreciente. A ella acudían gentes de muy diversos puntos geográficos, germinando en su propio suelo diversos cultos de origen oriental: Isis, Serapis, Mithra (BENDALA, 1982, 99 passim).

En este contexto, el culto imperial, fomentado en todos los lugares del Imperio, cumplió en Mérida un papel especial. El emperador debía estar siempre presente entre los habitantes de una población tan numerosa y cuya misión como ciudad era la de controlar un vasto territorio alejado del centro del Imperio. La divina Maiestas del emperador debía además triunfar sobre otras divinidades a las que los emeritenses rindieran culto. No es de extrañar, por tanto, encontrar en Mérida tantas muestras de culto al em-

(9) TERT, De Spectaculis, X. 1-2, ed. T. R. Glover.: Transeamus ad scaenicas res, quarum et originem communem et titulos pares secundum ipsam ab initio ludorum appellationem et administrationem coniunctam cum re equestri iam ostendimus.... 


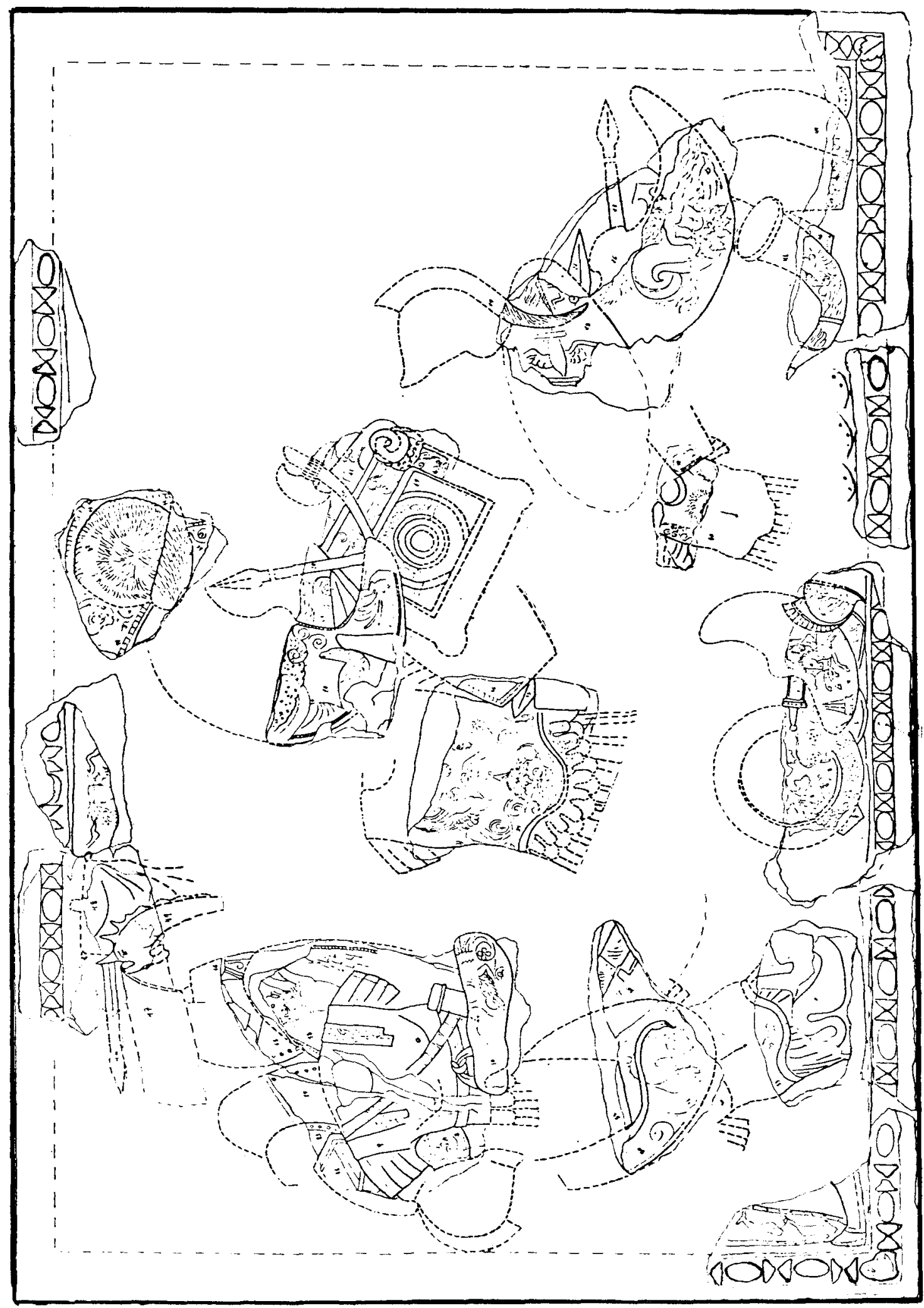

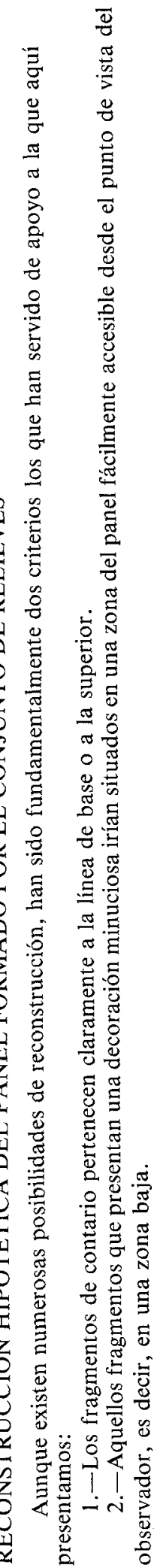


perador (ALVAREZ MARTINEZ, 1976, 43 passim; ídem, 1982, 53 passim), entre los que hay que incluir este sacellum del peristilo del teatro.

\section{ORIGEN Y SIGNIFICADO DEL TEMA DE LAS ARMAS AMONTONADAS}

La iconografía de la guerra posee un amplio repertorio en el mundo romano, sobre todo si se tiene presente que uno de los pilares fundamentales de la propaganda política imperial lo constituía el culto a la Viçtoria del Emperador. El mundo de las artes visuales se hizo especialmente sensible a la hora de plasmar esta idea del «Triunfo Imperial».

En el ámbito de las artes plásticas - por centrarnos en el tema que nos ocupa- encontramos la representación de este concepto de maneras diferentes: desde la configuración de escenas con personajes, hasta la evocación del triunfo mediante la casi total abstracción de esta idea. Algunos ejemplos pueden ilustrar bien esta sucesión de fases conceptuales:

I.-Escenas en las que se representa la ceremonia del triumphus del Emperador: jarras de Boscoreale (KÄHLER, 1958, taf. 145), relieves triunfales del arco de Tito (BIANCHI BANDINELLI, 1969, f. 237-241), Gemma Augustea (BIANCHI BANDINELLI, 1969, f. 209).

II.-Escenas de batallas y campañas militares en las que se representa al ejército romano y al enemigo: las guerras dácicas, historiadas en el fuste de la Columna de Trajano (LA COLONNA TRAIANA, 1942), las guerras párticas, en el fuste de la Columna Aureliana (LA COLONNA ANTONINIANA, 1942), relieves del Gran Zócalo del arco de Orange (AMY, DUVAL, ..., 1962, pl. 28, 29, 30).

III.-Escenas de reducción de enemigos por parte de soldados o del emperador mismo: relieve triunfal de Maximiliano Hercúleo, en Mérida (ARCE, 1982), estelas de legionarios de caballería auxiliar: (ROBINSON, 1975, núm. 301, 302, 303, 304).

IV.-Maniquí-Tropaeum con personajes (cautivos, alegorías de pueblos vencidos, divinidades): fachadas este y oeste del arco de Orange (AMY, DUVAL, .., 1962, pl. 6, 19, 20), Gemma Augustea (BIANCHI BANDINELLI, 1969, f. 209), casco de Pompeya (PICARD, 1957, pl. XIII).

V.-Maniquí-Tropaeum, revestido de armas: trofeo galo de Pompeya (PICARD, 1957, pl. VII), trofeo cesariano de Pompeya (PICARD, 1957, pl. VII), trofeo de Domiciano (BIANCHI BANDINELLI, 1969, f. 247).

VI. - «Armas amontonadas» o congeries armorum con tropaeum u otras figuras como elementos secundarios: relieves del «templo de Marte» en Mérida (LEON, 1970, 181-197), relieves de Bolonia (PICARD, 1957, pl. XXIX), friso de Cumas, en Berlín (REINACH, II, 1912, p. 36; PICARD, 1957, 354, tav. XIV).

VII. - «Armas amontonadas» 0 congeries armorum como elemento único y principal: armas de los paneles del arco de Orange (AMY, DUVAL, .., 1962, 77, tav. 16-20, 43-47, 49, 75-82), relieve de Bolonia (PICARD, 1957, tav. XXVIII-XXIX), urna de Agnani (LOVATELLI, 1900, 249, tav. XIV-XV), pilastras del Armilustrum del Aventino (CROUS, 1933), ara funeraria de M. A. Ianuarius (ALTMANN, 1902, 213), relieves del zócalo de la columna de Trajano (LA COLONNA TRAIANA, 1942), panel cuadrangular del British Museum (SMITH, 1904, 426, f. 69), bloque del Museo de Antigüedades de Burdeos (ESPERANDIEU, II, 1908, 211-212), relieve del Museo de Turín (WEGNER, 1961, 272), relieve del Museo de Parma (WEGNER, 1961, 272), fragmento de un relieve del Museo de Tirana (WEGNER, 1931, 64, Abb. 1, 2), relieve de la catedral de Téramo (FUHRMANN, 1941, f. 56-57), base de la columna de Antonino Pio, en la que aparecen a los pies de la diosa (BIANCHI BANDINELLI, 1969, f. 321), fragmento del Museo Campano de Capua (WEGNER, 1961, 272, tav. 54), fragmento del Museo Nacional de Nápoles (WEGNER, 1961, 272), fragmentos de entablamento de la Domus 
Flavia (DURRY, 1921, 303), paneles del monumento funerario de Neumagen (KÄHLER, p. 421, III, 19), Porte Noire de Besançon (ESPERANDIEU, VII, 1918, 5), Apoteosis de Claudio (BLANCO, 1957, 115).

En España, encontramos los siguientes ejemplos:

1.--Relieve de Coria (DIAZ MARTOS, 1957-58).

2.-Fragmento de friso de mármol blanco de La Alcudia de Elche (RAMOS FOLQUES, 1962-63).

3.-Relieves de Clunia (ACUÑA, 1974).

4.-Relieves del «templo de Marte» de Mérida (LEON, 1970, 181-197).

5.-Relieves del Mausoleo de Sofuentes (FATAS y MARTIN BUENO, 1977, 232).

6.-Relieves de San Esteban de Gormaz (GARCIA MERINO, 1977, 361).

\section{EL TEMA DE LAS ARMAS AMONTONADAS}

Nos centraremos en este punto por ser este el tema que se representa en el conjunto que estudiamos.

El primer problema al que nos enfrentamos cuando lo abordamos, es la confusión generada tras denominar bajo un único término - «trofeo»- dos temas que originalmente son diferentes.

En sentido genérico y casi en lenguaje coloquial se ha llamado «trofeo» a cualquier recordatorio del triunfo en una contienda. Cuando se aplica esta denominación a la plástica del mundo clásico se engloban bajo este título tanto al maniquí con armas como al túmulo de las mismas.

Mientras que en Grecia clásica ambos temas se conocían con una única denominación, Roma - considerándolos entidades distintas - les impuso términos diferentes. Así, Tácito, cuando comenta la victoria de las tropas de Germánico, dice que levantaron una congeries armorum (10) y un tropaeum (11), es decir, un túmulo de armas amontonadas y un maniquí.

También, aunque ya en el siglo III d. C., encontramos que Herodiano hace también esta diferenciación terminológica en lengua griega: al hecho de levantar un maniquí

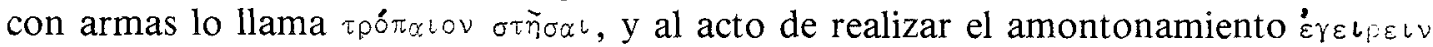
(PICARD, 1957).

Pero tanto la costumbre de acumular armas como la de levantar un tropaeum, responden esencialmente a una misma concepción mágica de la guerra.

En la mayoría de los pueblos de pensamiento mítico - y entre ellos hay que incluir al griego- las armas han llegado a convertirse en un fetiche. En un arma está depositada la capacidad de morir o de seguir viviendo. Por ello, es una creencia bastante generalizada la de que, después de una contienda, las armas quedan profundamente sensibilizadas por la Fuerza o Fuerzas devastadoras que hicieron posible la victoria, y por los espíritus de los que las usaron. De ahí la variedad de rituales que tienen lugar después de las batallas.

Es un profundo sentido apotropaico el que anima, por ejemplo, a no dejar esparcidas las armas del enemigo por el campo de batalla, a no permitir que las fuezas del Mal se extiendan y puedan volverse contra el vencedor. Esta costumbre, según cuentan Tito se extiendan y puedan volverse contra el vencedor. De ahí que se reúnan las armas for-

(10) TACITO, ANNALES, II, XVIII, 1: ... Miles in loco proelii Tiberium imperatorem salutauit struxitque aggerem et in modum tropaeorum arma subscriptis uictarum gentium nominibus imposuit.

(11) TACITO, ANNALES, II, XXII, 1: Laudatis pro contione uictoribus Caesar congeriem armorum struxit, superbo cum titulo: debellatis inter Rhenum Albimque nationibus exercitum Tiberii Caesaris ea monimenta Marti et Iovi et Augusto sacrauise. 
mando montones o túmulos. Esta costumbre, según cuenta Tito Livio (12) y César (13) en diferentes pasajes, estaba bastante extendida entre los pueblos gálicos.

Los griegos también solían formar túmulos con las armas, pero no para dejarlas abandonadas sino para quemarlas a continuación.

Las armas - los escudos especialmente- podian también ofrecerse como símbolo de victoria a un dios asociado a la guerra. Cuenta Pausanias cómo los lacedemonios, después de su contienda contra los atenienses, argivos y jonios, dedicaron un escudo dorado en el templo de Tanagra.

Roma también continuó esa costumbre y así, según el mismo autor, tras la victoria sobre los aqueos, el general Mummius y su ejército ofrecieron más de veinte escudos en el santuario de Olympia, colgándolos alrededor del friso, por encima de las columnas (PAUSANIAS, V, 10. 4-7).

El acto de levantar un maniquí-tropaeum, responde al mismo sentido apotropaico que veíamos para la formación de una congeries armorum, pero mientras que este último es una práctica común a varios pueblos, el tropaeum es algo específico del pueblo griego (PICARD, 1957) y, según Reinach, pertenece a un estadio evolutivo superior.

Para entender este caso excepcional no hay que olvidar lo que en esencia constituía la clave del pensamiento griego; tal era precisamente otorgar al hombre, como ser terrenal, un papel muy superior al que otras culturas le habian concedido. De la misma manera que crearon unos dioses «humanizados» y centraron el objeto de su arte en el estudio del cuerpo humano, también dieron un carácter antropomorfo a esa concentración de fuerzas malignas construyendo el tropaeum.

El paso siguiente a éste fue identificar esa expresión de la Fuerza con Zeus tropaios.

La costumbre de levantar el tropaeum pasó de Grecia a Roma ya en época temprana — quizás en el siglo II AC - si bien no faltan en esta última —en su afán de búsqueda de una identidad nacional - relatos legendarios que abogan por un origen itálico del tema. Tal es el caso del mito de Tarpeia (GANSINIEC, 1949). Según relata Dionisio de Halicarnaso, la joven Tarpeia, doncella del reino de Rómulo, accedió a abrir las puertas de la ciudad a los sabinos bajo la condición de que éstos recompensaran su traición regalándola y colocando encima de ella todas las joyas que llevaran. Tarpeia abrió las puertas y los sabinos no sólo le dieron las joyas, sino que colgaron sobre ella todos sus escudos, aplastándola y causándole la muerte (PICARD, 1957, 107-108).

En cuanto al acto de amontonar armas - que, como se ha dicho, fue algo practicado inicialmente por los galos - pasó a ser una costumbre que el ejército romano adoptó durante las campañas de César en las Galias y que probablemente sufriría una cierta asimilación con alguna otra costumbre ancestral romana, como la de colgar las armas en las puertas de la ciudad o del Armilustrum.

Aunque la congeries armorum o el tropaeum no fueran algo específicamente itálico, la mentalidad romana impuso sobre ellos su huella de tal manera, que el resultado conceptual varió en un aspecto fundamental. De la misma manera que el espíritu individualista de la mentalidad romana conduce a la creencia de que la victoria en una batalla es resultado de la fuerza sobrenatural de un único individuo, el tropaeum o la congeries armorum simbolizan la Fortuna y la Felicitas de un solo personaje, del triumphator.

El sello de Roma también se impondrá en otro aspecto; si bien en sentido genérico se siguieron representando las diferentes armas de pueblos vencidos, se añadió al reper-

(12) TITO LIVIO, V, 39, 1.: Gallos quoque velut obstupefactus miraculum victoriae tam repentinae tenuit, et ipsi pavore defixi primum steterunt velut ignari quid accidisset; deinde insidias vereri; postremo caesorum spolia legere armorumque cumulos, ut mos eis est, coarcevare...

(13) CAESAR, Bell. Gal., VI, 17:... Multis in civitatibus harum rerum exstructos tumulos locis consecratis conspicari licet. 
torio el propio armamento romano. Un ejemplo ilustrativo lo tenemos en el arco de Orange, donde al lado de las armas típicamente gálicas - scutum oval, carnyx, ... aparecen las romanas.

Todo lo tratado hasta el momento sobre el origen y evolución del tema de las armas amontonadas invita a trasladarnos a un problema que ha sido planteado especialmente con relación a este último: si la congeries armorum sustenta un valor simbólico en el conjunto de las decoraciones o si simplemente desempeña un papel ornamental.

Como cuestión previa al análisis de esta cuestión, es fundamental trasladarse desde la perspectiva contemporánea, que observa con ojos laicos la mayoría de las expresiones plásticas, a la óptica del mundo antiguo en que cualquier fenómeno podía ser interpretado según las coordenadas del pensamiento mítico. Si además, nos situamos en la mentalidad romana, más mediatizada por el fetichismo y la superstición que por actitudes puramente religiosas, ese valor simbólico otorgado a ciertos actos y objetos se potencia enormemente.

Las claves iconográficas en el mundo antiguo, aunque no fueran comprendidas plenamente por todos los receptores, no estaban, por ello, exentas de un profundo simbolismo en la mayoría de los casos. Habrá que esperar al Renacimiento para que el lenguaje plástico de época clásica se utilice desposeido de su contenido ideológico original. Es difícil concebir en la Antigüedad la existencia del arte por el arte. Incluso si estudiamos esa decoración que se ha dado en llamar «ornamental», encontramos un trasfondo ideológico. Me refiero a la tan utilizada decoración vegetal (roleos, acantos, volutas, palmetas...) a la que Roma - tras heredarla del mundo helenístico-dará un contenido nuevo, esparciéndola por el Ara Pacis para así simbolizar la «prosperidad, paz y riqueza de la nueva era augustea». Es evidente que así como hay símbolos que evolucionan más rápidamente desde su significado original y pasan a esa otra parcela de la evocación inconsciente - del signo-, otros tardan más en perder su contenido inicial, precisamente por aludir a temas más concretos.

Se ha visto anteriormente, cómo la costumbre ancestral de signo apotropaico de amontonar armas, pasó en Grecia a simbolizar la victoria por mediación de los dioses, y cómo, en época romana, la propaganda imperial hizo uso de este tema para la evocación de la Virtus y la Fortuna del Emperador. Pero esta evocación tendrá matices diferentes según los distintos contextos en que este tema aparezca.

\section{DIFERENTE LOCALIZACION DEL TEMA DE LAS ARMAS AMONTONADAS}

La primera vez que encontramos representadas armas amontonadas es en época helenística. Se acumulan como trofeo de guerra y signo de victoria bajo los pies de la estatua de Etolia, en Delfos (COURBY, II, p. 288). Pero en este caso, como en algunos más, no ha adquirido aún la autonomía y entidad propia que llegará a poseer en época romana. En este contexto no deja de ser un elemento muy secundario dentro de la composición global del tema.

Otro emplazamiento en el que puede aparecer la congeries armorum son los templos. Lo vemos en el Friso de Atenea Polias en Pérgamo (BOHN, 1885, 38) en fustes de columnas pertenecientes probablemente a templos (columna caelata del Perigueux) (ESPERANDIEU, 1908, 248).

La aparición en un espacio religioso, como es el templo, ratifica el valor simbólico de las distintas representaciones que allí puedan localizarse. Por otra parte, ya se ha comentado anteriormente cómo Roma adoptó la costumbre de colgar los escudos en los templos. En definitiva, decorar el templo de una divinidad con armas es ofrecerle la victoria; y es esperar, al mismo tiempo, el beneplácito divino. 
Otro de los lugares más típicamente romanos, y también de carácter religioso, es el Armilustrum. Consistía este recinto, según las descripciones de Varrón, Paulus y Plutarco, en un espacio circular en cuyo centro se erigía la estatua de Marte. Se entraba a él por un pórtico con columnas o pilastras, en las que se tallaba, generalmente, este tema de las armas.

Este es el caso, precisamente, de las pilastras de la galería de los Uffizi, que según Willen Crous, flanqueaban la entrada al Armilustrum del Aventino, en Roma (CROUS, 1933).

Idéntica función desempeñaría, con toda probabilidad, el friso del Staatliche $\mathrm{Mu}$ seum de Berlín, encontrado en Cumas (REINACH, II, 1912, 36), e igualmente los paneles que constituyen los sofitos del «templo de Marte» de Mérida - posibilidad ésta ya sugerida por P. León (LEON, 1970, 181).

En el Armilustrum tenía lugar cada año la purificación ritual de las armas, en el curso de una fiesta denominada «Armilustrium».

Otro marco en el que con frecuencia encontramos frisos de congeries armorum es el mundo funerario. Ejemplos muy significativos son la urna de Agnani (LOVATELLI, 1900, 249), el ara funeraria de M. A. Ianuarius (ALTMANN, 1905, 271) y la urna de C. Sulpicius Platorinus (GUSMAN, 1912, pl. 75). ¿Cuál sería el sentido de las representaciones de armas en este ámbito? Las conclusiones no están claras. Mientras que Altmann considera el papel de estas decoraciones como exclusivamente ornamentales, creo poder contar con algunos argumentos favorecedores de una valoración simbólica.

En primer lugar, cuesta pensar que la gratuidad o el puro azar sean los que determinen en última instancia la decoración de un ambiente de ultratumba y en un contexto de fondo como es la fetichista mentalidad romana.

Pero, además de esto, conviene recordar el amplio sentido que puede poseer el concepto de Victoria. La Victoria, en sentido genérico, no sólo se entiende como la gloria del Emperador sobre el ejército vencido; también se puede vencer a la muerte, incorporándose así a la otra vida (PIGANIOL, 1923, 116-126).

Sabemos, por otra parte, que tras la muerte de algún personaje importante se solían celebrar juegos en el circo -el mismo tipo de juegos que se celebraban en honor a la Victoria o al Triunfo del Emperador.

Creo que es éste el sentido que puede tener un friso de armas en una tumba; pero si rechazáramos esta posibilidad, todavía quedaría otra, que, aunque de forma más leve, seguiría imprimiendo un cierto carácter simbólico a la decoración. Tal sería la vinculación del personaje enterrado con el ejército: la evocación de alguna de sus «gloriosas» batallas o simplemente el disfrute en vida de algún cargo militar.

Con todo esto, es más fácil pensar en el carácter simbólico de esta decoración, que no en un valor puramente ornamental.

Volviendo sobre el tema de los distintos emplazamientos de la congeries armorum, donde sin duda lo encontramos más ampliamente representado es en aquellos monumentos alusivos al triunfo por antonomasia: los arcos de triunfo y las columnas historiadas.

Sobre el primero de estos dos casos, contamos con una larga lista de ejemplos repartidos por todo el Imperio Romano. Es frecuente encontrar frisos y paneles de armas junto a otras muchas expresiones de la propaganda política imperial (escenas de batallas, de triumphus, trofeos...) Muchos de los paneles de congeries armorum que encontramos repartidos por numerosos museos pudieron haber pertencido a un arco triunfal (panel cuadrangular del Museo Británico, paneles de los museos de Burdeos, Perigueux... Ver páginas anteriores). 
En cuanto al segundo de los casos - la columna historiada - la realción entre el poder propagandístico de la narración de las batallas y la expresión de la Victoria - la congeries armorum - es evidente.

Incluso podría pensarse en un cierto valor simbólico de ofrenda a la Felicitas del Emperador, evocada y expresada por la majestuosidad de la columna. De la misma manera que en Grecia se ofrecen armas a los pies de Etolia, Roma ofrece el armamento al Emperador triumphator, representado por sus campañas y victorias.

Por último, otro de los emplazamientos del tema de la congeries armorum son - como aquí se ha propuesto- los templos o sacella dedicados al culto imperial. Sin embargo, el hecho mismo de aparecer en un contexto de culto imperial, le confiere un significado muy específico. Este significado lo hemos visto ratificado en los mismos relieves emeritenses, cuando se ha estudiado páginas atrás el tipo de armamento que se representa - de cuerpos de alto status y del Emperador-. La evocación en estos casos concretos no sería la del poder genérico del Emperador - como en la mayoría de los casos-; sino la persona misma del Emperador, en su dimensión militar, y como portador de la Virtus y la Fortuna.

\section{CONCLUSIONES}

Los relieves emeritenses que aquí se han presentado constituyen la expresión plástica del tema de las «armas amontonadas» o congeries armorum.

Este tema tiene su origen en una antigua constumbre que consistía en formar túmulos con el armamento que quedaba después de una batalla. Este rito apotropaico fue practicado originalmente por los galos y más tarde adoptado por el ejército romano, sintetizándose a la vez con antiguas costumbres romanas, como la de colgar las armas en la entrada de la ciudad y del Armilustrum.

Aunque los precedentes de la representación plástica de este tema los encontramos ya en el siglo III AC, su verdadera entidad e independencia tendrá lugar en época romana; se convirtió entonces en un símbolo de victoria asociado, generalmente, al triunfo de un determinado general y más tarde del Emperador.

En el caso de los relieves emeritenses, la virtus y la felicitas imperial se expresan mediante los signos propios del emperador: la coraza imperial, la corona "cívica», la pelta y un elemento de especial interés; la escena de los ludi scaenici, en el que además figura el símbolo de la libertad alcanzada por el triunfo; el pileus. La alusión al Emperador mismo se encuentra, a su vez, ratificada por el lugar donde aparecieron los relieves: un sacellum dedicado al culto imperial. La función de este recinto cultural iría íntimamente ligada a los desfiles procesionales que discurrirían por el peristilo y que formarían parte de la pompa scaenici.

La cronología del conjunto de relieves se ha establecido en base al estudio de los temas decorativos y al lenguaje formal en ellos utilizados, pero la mayor precisión, en este sentido, se ha alcanzado por el análisis estilístico en las dos vertientes en que éste se expresa: la estructura compositiva y la plástica formal o de detalle.

Según la información que proporcionan todos estos datos, parece que la datación se inclina a fijarse en un momento avanzado del período julio-claudio. 


\section{BIBLIOGRAFIA}

ACUÑA FERNANDEZ, P. 1974: «Los relieves romanos de Clunia decorados con motivos militares». Studia Arqueologica, 30. Valladolid.

- 1975 b: Esculturas militares romanas de España y Portugal. I. - Las esculturas thoracatas. Roma. ALSCHER, L. 1942: Die fliegende Nike. München.

ALTMAN, W. 1905: Die Römischen Grabaltäre der Kaiserzeit. Berlin.

ALVAREZ MARTINEZ, J. M. 1976: «El templo de Diana». Actas del Simposio Internacional conmemorativo del Bimilenario de Mérida, pp. 43-55. Madrid (A. S. I. B. M.).

- 1981: El puente y el urbanismo de Augusta Emerita. Madrid.

- 1982: «El Foro de Augusta Emerita». Homenaje a Sáenz de Buruaga. Madrid, pp. 53-69.

ALVAREZ SAENZ DE BURUAGA, J. M. 1976: «La fundación de Mérida». A. S. I. B. M., pp. 19-33. Madrid.

- 1980: «Observaciones sobre el teatro romano de Mérida». Simposio sobre el teatro romano en Hispania. Mérida (en prensa).

AMY, R.; DUVAL, P.; FORMIGE, J.; HATT, J.; PICARD, CH.; PICARD, G. CH.; PIGANIOL, A. 1962: «L'arc d'Orange». Supplement a «Gallia» XV. Paris.

ARCE, J. 1982: «Un relieve triunfal de Maximiano Herculeo en Augusta Emerita y el Pap. Argt. Inv. 480». Madrider Mitteilungen 23 (en prensa).

- 1984: «Publio Carisio y la fundación de Augusta Emerita». Lucentum III. Alicante.

BARINI, C. 1952: Triumphalia. Imprese ed onoro militari durante l'Imperio romano. Torino.

BAUDRILlART, A. 1894: Les Divinités de la Victoire en Grece et en Rome. Paris.

BECATTI, G. 1960: La Colonna coclide Istoriata. Roma.

BENDALA, M. 1982: «Reflexiones sobre la iconografía mitraica de Mérida». Homenaje a Sáenz de Buruaga. Madrid, pp. 99-109.

BIANCHI BANDINELLI, R. 1969: Roma. Centro de poder. Madrid.

BISI, A. M. 1965: «Il grifone. Storia di un motivo iconografico nell'antico oriente mediterraneo». Studi Semitici $n .{ }^{\circ}$ 13. Roma.

BLANCO, A. 1982: En Historia de España (R. M. Pidal), 2. ${ }^{2}$ ed., vol. II, 2. Madrid, 1982.

BOBU FLORESCU, F. 1969: Die Trajanssäule. Grundfragen und Tafeln. Bonn.

BRILliANT, R. 1963: «Gesture and Rank in Roman Art». Memoirs of the Connecticut Academy of Arts and Sciences.

CANDIDA, B. 1979: Altari e cippi nel Museo Nazionale romano. Roma.

CAPUTO, G. 1950: «Architettura del teatro di Leptis Magna». Dionisio, XIII.

CARTON, L. 1902: «Le théâtre romain de Dougga». Mémoirs presentés par divers savants à l'Académie, $X I$.

CIANFARANI, V. 1951: «Spino-Teatro: campagna di scavo 1950». Nsc., Ser. VIII, vol. V.

COARELLI, F. 1968: «Il tempio di Diana "in circo Flaminio" ed alcuni problemi connessi». Dialogui di Archeologia $n .^{\circ} 2$.

COLONNA TRAIANA, LA. 1942. Roma XIX.

CORZO, R. 1976: «In finibus emeritensium». A. S. I. B. M., p. 217.

COUSSIN, P. 1926: Les armes romaines. Paris.

- 1927: «Les armes gauloises». Rev. Archéologique I.

DELPLACE, C. 1980: Le Griffon. De l'Archaisme à l'époque imperiale. Etude iconographique et Essai d'interpretation symbolique. Institute Historique Belge de Roma.

DIAZ MARTOS, A. 1957-58: «El relieve romano de Coria». Ampurias 19-20.

DURR, M. 1921-23: «Les Trophées Farnèse». Mel. Histoire et Archaelogie XXXIX-XL, p. 303 ss.

ESPERANDIEU, E.: Recueil géneral de Bas-reliefs de la Gaule romaine. Paris, 1907-1918.

FERNANDEZ CHICARRO, C. 1946: «La estatuaria militar romana de época imperial en el Museo Arqueológico Provincial de Sevilla». M. M. Arq. Provinciales VII, pp. 128-136.

FLACELIERE, R. 1937: Les Aitoliens a Delphes. Paris.

FLORIANO, A. 1944: «Excavaciones en Mérida». A. Esp. A. 54-57, pp. 151-186.

FORMIGE, J. 1950: Le théâtre romain de Vienne. Vienne.

FORNI, G. 1982: «La popolazione di Augusta Emerita». Homenaje a Sáenz de Buruaga. Madrid.

FREZOULS, E. 1952: «Teatri romani dell'Africa francese». Dionisio XV.

GAGE, J. 1930: «L'epée du British Museum». Rev. Arch. XXXIII.

GANSINIEC, Z. 1949: Tarpeia, the making of a myth. Wroclaw.

GOUREVITCH, D. 1968: "Le chien, de la thérapeutique populaire aux cultes sanitaires». Mélanges d'Arch. et d'Hist. LXXX, p. 247.

GSELL, S. 1901: Les monuments antiques de l'Algérie, I. Paris.

GUSMAN, P. 1912: L'Art Decorative de Rome. Paris. 
HAMBERG, G. 1945: Studies in Roman Imperial Art. Uppsala.

HANFMANN, G. 1951: The Season Sarcophagus in Dumbarton Oaks. Massachussetts.

HANSON, A. 1959: Roman theater-temples. Princeton.

HÖLSCHER, T. 1967: Victoria Romana. Mainz.

HONROTH, M. 1971: Stadtrömische Girlanden. Wien.

JORGE ARAGONESES, M. 1968-69: «El vaso ibérico de Santa Catalina del Monte». A. Esp. A. 42, página 200

KLUMBACH, H. 1974: Römische Helme aus Nieder Germanien. Bonn.

KÄHLER, H. 1948: Der grosse Fries von Pergamon. Berlin.

- 1958: Rom und seine Welt. München.

LANTIER, R. 1918: Monuments sculptés pre-chrétiens de la Peninsule Iberique. Paris.

LEON, P. 1970: «Los relieves del templo de Marte de Mérida». Habis I, p. 180.

LE ROUX, P. 1982: L'armée romaine et l'organisation de province iberique d'A uguste à l'invasion de 409. Paris.

LIPPOLD, G. 1956: Die Skulpturen des Vaticanischen Museums. Berlin.

LÖWY, E. 1928: Die Anfänge des Triumphsbogens. Wien.

MACIAS, M. 1929: Mérida monumental y artística. Barcelona.

MANSUELLI, G. A. 1958: Galleria degli Uffizi. Le Sculture I. Roma.

MARDSEN, E. W. 1969: Greek and Roman Artillery. Historical Development. Oxford.

- 1971: Greek and Roman Artillery. Technical Treatises. Oxford.

MATTINGLY, H. y SYDENHAM, E. 1923-1968: The Roman Imperial Coinage, volúmenes I-III. London.

MAXFIELD, V. 1981: The military decorations of the Roman Army. University of California Press.

MAYENCE, F. 1939: «La VI ${ }^{e}$ campagne de fouilles à Apamée». Ant. Cl VIII.

MELIDA, R. 1925: Catálogo monumental de España. Prov. de Badajoz. Madrid.

MELIDA, R. y MACIAS, M. 1932: «La postescena del teatro de Mérida» Mem. Junta Sup. Exc. Arq. 118, p. 13.

PICARD, G. 1957: Les Trophées romains. Paris.

PIGANIOL, A. 1923: Recherches sur les jeux romains. Strasbourg.

PUIG I CADAFALCH, J. 1934: L'arquitectura romana a Catalunya. Barcelona.

RAMOS FOLQUES, A. 1962-63: «Unos pozos manantiales de época romana en La Alcudia de Elche». A. Esp. A. 35-36.

ROBERT, C. 1969: Die Meerwesen auf den Antiken Sarkophagreliefs. Roma.

ROBINSON, 1975: The Armour of Imperial Rome. London.

RUMPF, A. 1939: Die Meerwesen auf den Antiken Sarkophagreliefs. Berlin.

SARIA, B. 1938: «Das Theater von Stobi» AA, LIII, pp. 135-144.

SCOTT, K. 1936: The Imperial Cult under the Flavians. Stutgart.

STEINER, P. 1906: «Die dona militaria». BJ 114-115. Bonn.

STEMMER, K. 1978: Untersuchungen zur Typologie, Chronologie und Ikonographie der Panzerstatuen. Berlin.

STRONG, D. E. 1966: Greek and Roman Gold and Silver Plate. London.

STUVERAS, R. 1969: «Le putto dans l'art romain». Latomus XCIX.

TADDEI, G. 1930: «La Vittoria in volo». Italia Numismatica $n .^{\circ} 3$.

TRAVERSARI, G. 1971: L'Arco dei Sergi. Padua.

VERMEULE, C. 1959-60: «Hellenistic and Roman cuirassed statues». Berytus XII.

WEGNER, M. 1957: Ornamente kaiserzeitlicher Bauten Roms Soffiten. Köln.

- 1961: «Kapitele und Frieze vom Bogen der Sergier zu Pola». B. J. 161, pn. 263-276.

WIESELER, F. 1851: Theatergebäude und Denkmäler des Bühnenwesens bei den Griechen und Römern. Göttingen.

WILLEN CROUS, J. 1933: «Florentiner Waffenpfeiler und Armilustrium». R. M. 48, p. 1-119. 